\title{
WestVirginiaUniversity
}

THE RESEARCH REPOSITORY @ WVU

Graduate Theses, Dissertations, and Problem Reports

2017

\section{Brook and Brown Trout Movement in a Restored Appalachian Watershed}

Benjamin Joseph Harris

Follow this and additional works at: https://researchrepository.wvu.edu/etd

\section{Recommended Citation}

Harris, Benjamin Joseph, "Brook and Brown Trout Movement in a Restored Appalachian Watershed" (2017). Graduate Theses, Dissertations, and Problem Reports. 5771.

https://researchrepository.wvu.edu/etd/5771

This Thesis is protected by copyright and/or related rights. It has been brought to you by the The Research Repository @ WVU with permission from the rights-holder(s). You are free to use this Thesis in any way that is permitted by the copyright and related rights legislation that applies to your use. For other uses you must obtain permission from the rights-holder(s) directly, unless additional rights are indicated by a Creative Commons license in the record and/ or on the work itself. This Thesis has been accepted for inclusion in WVU Graduate Theses, Dissertations, and Problem Reports collection by an authorized administrator of The Research Repository @ WVU. For more information, please contact researchrepository@mail.wvu.edu. 


\author{
Benjamin Joseph Harris
}

Thesis submitted to the

The Davis College of Agriculture, Natural Resources \& Design

at West Virginia University

in partial fulfillment of the requirements for the degree of

\author{
Master of Science \\ In
}

Wildlife and Fisheries Resources

\author{
J.Todd Petty, Ph.D., Chair \\ Jeff Hansbarger, M.S. \\ Kyle Hartman, Ph.D. \\ Wildlife and Fisheries program \\ In the Division of Forestry and Natural Resources
}

Morgantown, West Virginia

2017

Keywords: Brook Trout, Brown Trout, Habitat Restoration, Fish Movement Copyright 2017 Benjamin Harris 


\begin{abstract}
BROOK AND BROWN TROUT MOVEMENT IN A RESTORED APPALACHIAN WATERSHED
\end{abstract}

\author{
Benjamin Joseph Harris
}

Understanding the localized ecological impacts of large-scale environmental (i.e., land use and climate) change is of critical importance not only to scientists tasked with natural resource management, but also individuals and communities across the world. In the Appalachian Mountains of the eastern United States, Brook Trout Salvelinus fontinalis serve as a key indicator species for the integrity of stream habitats. Brook Trout populations have largely declined throughout their native range, with impending climate change and thermal habitat exclusion potentially reducing Brook Trout habitat by more than $50 \%$. Therefore, it is imperative that we understand interactions between Brook Trout and the changing thermal landscape, as well as their responses to management projects designed to mitigate effects of land use and climate change. We conducted a telemetry study within Shavers Fork, West Virginia, to assess Brook and Brown Trout Salmo trutta response to restoration activities which were designed to create thermal refugia and improve Brook Trout habitat suitability in the main-stem channel while increasing fish access to previously severed tributary systems. The objectives of this study were to 1) quantify Brook and Brown Trout movement and habitat use throughout a high-elevation watershed consisting of a restored mainstem stream channel and reconnected tributaries, comparing these results to a prerestoration study; and 2) determine association of native and exotic trout with restored habitat structures on the mainstem channel.

We implanted 51 Brook Trout and 13 Brown Trout with radio transmitters during two field seasons from June 1-3, 2015 (23 Brook Trout and 5 Brown Trout) and June 14, 2016 (28 Brook Trout and 8 Brown Trout) and tracked the movements of 38 Brook Trout and 11 Brown Trout through August 15, 2015 and 2016 On average, Brook Trout moved greater total distances from their tagging site $(>3.00 \mathrm{~km})$ than Brown Trout $(<1$ $\mathrm{km}$ ), in some cases moving over $4 \mathrm{~km}$ in 24 hours. Brown Trout remained in the mainstem channel in all cases and associated with constructed habitat structures and natural pools. Analyses for relationships between Brook Trout and habitat structures show no verifiable response $\left(X^{2}=38.86, p=0.651\right)$, while there does appear to be an association between Brown Trout and structure pools $\left(X^{2}=14.24, p<0.001\right)$. Net Dispersal analyses indicate a difference $(t=1.70, p=0.02)$ in Brook Trout dispersal post versus pre-restoration. Comparisons of movement rates in Brook Trout using Kolmogorov-Smirnov tests also indicate a difference in rates of movement (meters/day) for Brook Trout from this study compared to those tagged in the pre-restoration survey $(D=0.35, p=0.02)$. These results confirm the importance of connected, continuous fluvial systems with accessible coldwater habitat in facilitating Brook Trout dispersal and maintaining large-scale metapopulation structure. Our study suggests that native fish communities may benefit more from the removal of dispersal barriers than structural habitat improvement on mainstem rivers, and that structural improvements in larger mainstems may have the unintended consequence of benefiting exotic species to the detriment of native species. 


\section{TABLE OF CONTENTS}

ABSTRACT

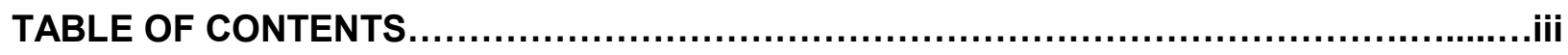

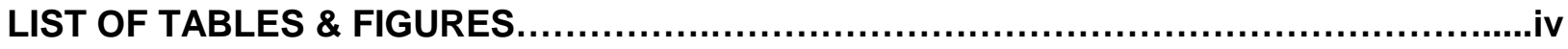

CHAPTER 1 - Literature Review

Reviewing the importance of fish movement within coldwater stream systems................1

CHAPTER 2 - Introduction

Trout movement within a restored Appalachian watershed........................................

STUDY AREA

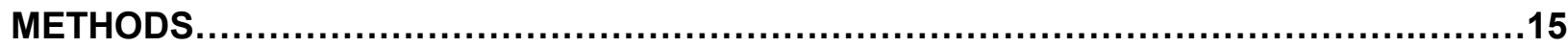

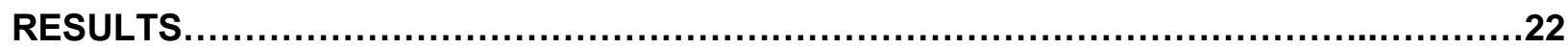

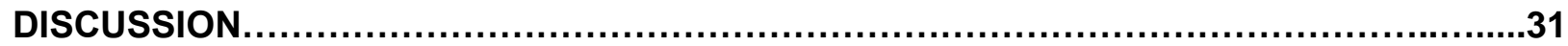

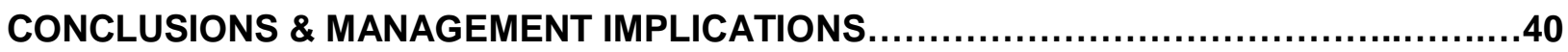




\section{니ST OF TABLES \& FIGURES}

Figure 1: Map of the upper Shavers Fork watershed

Table 1: Summary of Brook and Brown Trout size, dispersal and movement statistics throughout the 2015 field season

Table 2: Summary of Brook and Brown Trout size, dispersal and movement statistics throughout the 2016 field season

Figure 2: Movement and Dispersal of Brook and Brown Trout in the 2015 tagging group

Figure 3: Dispersal rates of Brook Trout tagged in the 2015 field season

Figure 4: Movement and Dispersal of Brook Trout in the 2016 tagging group

Figure 5: Dispersal rates of Brook Trout tagged in the 2016 field season

Figure 6: Hydrograph for the upper Shavers Fork system during the 2015 field season

Figure 7: Hydrograph for the upper Shavers Fork system during the 2016 field season

Figure 8: Map of the movement of Brown Trout 'SATR1/5', tagged in both the 2015 and 2016 tracking seasons

Figure 9: Cumulative frequency distributions of Brook and Brown Trout in the 2015 field season

Figure 10: Cumulative Frequency distributions of Brook and Brown Trout in the 2016 field season.

Figure 11: Dispersal rates for Brown Trout tagged in the 2015 field season

Figure 12: Dispersal rates for Brown Trout tagged in the 2016 field season

Figure 13: Map of final tracking locations for Brook and Brown Trout tagged in the 2015 field season

Figure 14: Map of final tracking locations for Brook and Brown Trout tagged in the 2016 field season

Figure 15: Photograph of the reconnected tributary access point at Lamothe Hollow

Figure 16: Photograph of the restored fish-access culvert on Oat's Run

Figure 17: Map of the fish located in the reconnected tributary Lamothe Hollow

Figure 18: Hydraulic Channel Unit Association by Brook Trout in the 2015 field season 
Figure 19: Hydraulic Channel Unit Association by Brown Trout in the 2015 field season Figure 20: Hydraulic Channel Unit Association by Brook Trout in the 2016 field season Figure 21: Hydraulic Channel Unit Association by Brown Trout in the 2016 field season Figure 22: Aerial photograph of intermittent floodplain tributary and map of Brook Trout occupancy

Figure 23: Map of final tracking locations for Brook Trout tagged at the 'Below $2^{\text {nd }}$ Fork' and 'East-West' surgery sites in the 2016 field season

Figure 24: Map of final tracking locations for Brook Trout tagged at the 'Above Ryan's Bend' surgery site in the 2016 field season

Figure 25: Map of surgery/tagging locations for the 2015 and 2016 field seasons 


\section{CHAPTER 1:}

\section{Reviewing the importance of fish movement within coldwater stream systems}

Climate change and its effects on aquatic ecosystems represent a pressing challenge to the management of coldwater stream habitats and native fish communities (Buisson et al. 2008). Recent climate analysis has provided increasingly strong evidence that streams and rivers in the United States are warming at greater rates than historically observed (Kaushal et al. 2010, Isaak et al. 2011). Fish species found in the Appalachian Mountain region of the eastern US are particularly impacted by this warming trend and the concomitant acidification of stream habitats through precipitation (McDonnell et al. 2015). These factors combine with large-scale historic anthropogenic influence in many watersheds, amounting to significant pressures on native fish communities (Hughes et al. 1998, Wagner et al. 2013). Coldwater habitat restoration efforts by management agencies have therefore largely been directed at increasing fish habitat availability by facilitating access to thermal refugia and restoring the connectivity of mainstem channels to their tributary systems and first-order streams.

Brook Trout Salvelinus fontinalis are one of the foremost species examined when assessing the ecological health of coldwater stream environments within the Appalachian region. Brook Trout therefore can serve as a key indicator species in evaluating the health of local aquatic communities (Kratzer \& Warren 2013); and represent a practical metric to assess the success of habitat improvement projects directed at increasing suitable habitat for native fish communities.

Brook Trout are the only salmonid native to the Appalachian Mountains and West Virginia, and they have been under population-wide pressure due to habitat loss and degradation (Petty et al. 2005; Menendez et al. 1998). Like most salmonids, Brook Trout exhibit high habitat selectivity based around thermal tolerance, substrate type and food availability 
(Meehan 1991, Petty et al. 2014). Brook Trout are therefore in many cases confined to the last high-elevation refuges in which there remain continual coldwater habitats with connected tributary systems (Marschall \& Crowder 1996). Studies have demonstrated a direct response in salmonids to alterations in both their physical habitat and water quality (De Jong et al. 1997; Beechie et al. 2014). Therefore, a common directive of fisheries management agencies is to restore in-stream habitat to improve suitability for various species of trout to facilitate populationwide benefits (Koljonen et al. 2013).

Habitat restoration efforts often attempt to reproduce processes observed in undisturbed stream systems, where the input of natural Large Woody Debris (LWD) is understood to be a critical component to the trophic ecology of stream fish (Sweka \& Hartman 2001). Sources of LWD have been reduced by intensive logging in many watersheds (Hartman \& Logan, 2010). LWD is additionally recognized to have a profound impact on available fish habitat and channel morphology- by altering depth, current and substrate type (Hildebrand et al. 1997). Large Woody Debris has been proven to be an important contributor to the natural formation of pool habitats in mainstem channels (Harvey et al. 1999). Therefore, the removal of large trees from high-elevation watersheds by logging activity can disrupt the deposition of LWD into the stream channel, leading to direct interactions with channel morphology, habitat availability and predation success. These interactions ultimately have a strong effect on the survivorship and viability of native fish populations (Hartman \& Hakala 2006).

One of the most direct methods for assessing the ecological response of organisms to their habitat is to observe the movement of individuals (Lima \& Zollner 1996). Areas of goodquality habitat should have low 'turnover' rate in movement of individual fish into and out of the area, whereas areas of poor quality habitat should have high 'turnover' rates (Harvey 1998). Animal 'movement' is described as small-scale motions used to locate optimal habitat or food resources. This is a separate term from 'migration', which defines the extended directional 
movement of whole populations as a necessary stage in their life cycle (Hansbarger, et al. 2008; Meyers et al. 1992; Gowan \& Fausch 1996).

Both movement and migration are necessary to allow stream-resident fishes to colonize new areas of habitat, facilitate successful spawning and enable gene flow throughout populations in a given watershed (Hansbarger, et al. 2008, Curry et al. 2002). The history of the study of stream fish movement has been a dynamic and changing one throughout the $20^{\text {th }}$ century. Immense amounts of human and financial capital are invested in the restoration of coldwater habitats throughout the United States every year. It is therefore a reasonable consideration that improving upon our understanding of metapopulation movement and response to habitat improvement in salmonids is of critical importance for informing biologists and empowering fisheries resource agencies to make management decisions on an impactful population-wide scale.

Early mark-recapture studies on the movement of stream-resident fishes (Gerking 1953, 1959) led to the belief that the majority of individual fish exhibited 'restricted movement' and a generally sedentary lifestyle (Shetter 1968, Cargill 1980), meaning that these fish mostly remained in the habitat units in which they were initially captured. Bachman (1984) provided documentation of sedentary lifestyles observed in Brown Trout in a Pennsylvania stream. However, many of these early studies of fish movement relied heavily upon certain fixed location mark-recapture methods which arguably led to a bias towards conservative estimates of fish movement (Curry et al. 2002, Rodriguez 2002).

The 'restricted movement paradigm' ideology of stream fish movement has since been challenged by a number of studies (Gowan et al. 1994, Mucha \& Mackereth 2008, Mollenhaur et al.2013) that called attention to a possible sampling bias towards the observation of sedentary individuals and minimization of movement behaviors. Additionally, Hughes (1999) demonstrated that the distribution of Arctic Grayling (Thymallus arcticus) throughout a river 
system was a function of numerous habitat variables, including water temperature and quality of feeding habitat. This provided at least some inference that in many cases fish moved throughout river systems to locate the most suitable habitat. Finally, Rodriguez (2002) argued that the scale and nature of a study will be a determining factor in whether researchers record movement as 'extensive', leading to a misunderstanding of the true nature of fish movement and ecology. This analysis included a critique of mark-recapture studies that likely misrepresented individual movement. Additionally, he explained the seasonal and specific timing of stream fish movement and migration. He also pointed out that fish populations are generally comprised of two components: one being highly mobile and one being mostly stationary. Each of these works represents a divergence from the previously accepted ideals of restricted movement in stream fishes.

In most cases, a practical way to assess the movement of fish is through radio or acoustic telemetry detection via the use of transmitter tags and receivers. In the aquatic environment, biotelemetry- the remote measurement of the behavior of free-living animals- is largely accomplished through the use of implanted or attached transmitter devices (Cooke et al, 2004). The two primary methods of remotely sensing signals from transmitter tags (acoustic \& radio) each have respective strengths and weaknesses which defines their suitability for different survey applications.

Acoustic biotelemetry was initially developed for use in aquatic surveys, and is therefore a commonly used method to assess the movement of individual fishes (Winter 1983). The proliferation of economical receivers and long-lasting acoustic transmitter tags has led to the widespread application of acoustic telemetry in the field of fisheries movement studies (Clements et al. 2005). However, acoustic biotelemetry surveys are best suited to deep, highconductivity aquatic habitats without 'noise' interference from turbulent water. Thus, acoustic biotelemetry is difficult to apply in many lotic environments- particularly high-gradient stream 
systems. Additionally, individual acoustic transmitters are identified by the receiver through determining differences in the pulse-rate, limiting the number of individuals which can be distinguished from a larger group.

Radio telemetry transmitters, on the other hand, were originally made for application in terrestrial wildlife studies, but were shortly thereafter modified to be suitable for aquatic surveys (Winter 1983). Radio transmitters function best in shallow, low conductivity water, and unlike acoustic transmitters their signal is not adversely affected by water turbulence. These qualities make radio transmitters the preferred choice for use in studies of fish movement in highelevation stream habitats. Radio transmitters also have the advantage of emitting a different frequency from each tag, making the identification of individuals simpler than in acoustic biotelemetry systems. However, radio transmitters are not well-suited for use in the marine habitat due to the much higher conductivity of salt water and the rapid loss of signal strength with increasing depth (Freund \& Hartman, 2002; Hartman \& Logan 2010).

In all fields of biotelemetry, technology is rapidly advancing and transmitters are increasing in battery life while still decreasing in size. Because transmitters have largely decreased in size, many trout movement studies have employed surgically-implanted tags. While anesthesia and surgery carry their own inherent risks and drawbacks, implanted tags are generally favored over those attached to the exterior of the fish due to the risk of entanglement, drag and potential loss of transmitter. Tags ingested into the stomach of fish generally have low retention rates through regurgitation and can interfere with feeding ecology of the animal (Hart \& Summerfelt, 1975). For these reasons, surgically implanted tags are commonly applied in trout movement studies. As long as certain surgical protocols and methodologies are followed, implanted tags have been demonstrated not to interfere with physiology or behavior of fish. Specifically, tags not exceeding $2.5 \%$ body weight typically have no observable impact on swimming performance or feeding ability of the fish (Winter 1983, Jepsen et al. 2002). 
Given recent studies and advances in technologies related to the study of movement, stream fish movement is now generally thought to be a more significant life history factor in individuals- allowing fish to find refuge from environmental (thermal) stress in addition to facilitating predator avoidance and access to limited food resources (Schlosser 1995, Brown \& Mackey 1995, Gowan \& Fausch 1996). Fish movement can be influenced and affected by a variety of factors, including water temperature, local population density, flow regime and fish size (Hansbarger, et al. 2008; Petty et al., 2012). Movement has additionally been established as a key component of 'ranging behavior' in stream fishes, tying closely to the concept of 'riverscape' ecology- which is based around the consideration of rivers and watersheds as continuous, interconnected systems (Fausch et al, 2002). 'Ranging behavior' is argued to comprise long-distance movement that ends when suitable habitat patches are encountered. Whereas migration in many fish species can readily be quantified and observed, movement can be a more subtle- but no less important aspect of the life history of an individual.

Several studies have demonstrated extensive seasonal movement in stream-resident salmonids, particularly Brook Trout (Rodriguez 2002, Curry et al. 2002, Petty et al. 2012). Hartman \& Logan (2010) described relatively high mobility and ranging behavior by Brook Trout in West Virginia streams. Tracking studies of inland trout in many cases (Clapp et al. 1990, Meyers et al. 1992, Young 1994) have demonstrated high-movement behaviors in individuals. Movement therefore likely plays an important life history role in fishes, given the immense energetic cost associated with high-mobility behaviors. It is believed that the movement of individuals allows for access to profitable foraging habitat patches. Thus, understanding movement behavior is a critical aspect of fisheries at the 'riverscape' scale and is vital to our ability to manage freshwater resources (Meehan 1991, Fausch et al. 2002).

Because trout are in at least some cases highly mobile individuals capable of selecting and occupying preferred habitat in response to seasonal and environmental cues (Gowan \& 
Fausch, 1996), they are suitable candidates to help researchers assess the impact of coldwater fisheries restoration initiatives- in fact, many coldwater restoration activities are specifically designed to benefit native coldwater species, such as Brook Trout and other salmonids. The study and understanding of native and exotic trout movement in response to habitat restoration initiatives is therefore a practical method for improving upon accepted methods of fisheries management and informing our response to climate change and other threats faced by coldwater stream ecosystems.

Movement and ranging are critical in the facilitation of gene flow, and these behaviors can also provide individual refuge from such population-wide selective pressures and catastrophic events as floods and wildfires (Minshall et al. 1989). Roghair (2005) argued that we must understand the ability of mobile components of fish populations to effect change on a metapopulation level in order to make sound management decisions in response to catastrophic events and watershed-wide population impacts. While there have been many recent studies on stream fish movement, the identification of causal mechanisms in trout, benthic and non-game fishes remain largely unknown (Petty \& Grossman 2004, Hansbarger, et al. 2008, Petty et al. 2012). There have been inquiries into trout movement in response to environmental factors such as water temperature and acidity (Gowan \& Fausch, 1996). There have, however, been few examinations of trout movement in direct response to restoration efforts aimed at increasing access to coldwater refuge habitats both in mainstem rivers and their tributaries. 


\section{CHAPTER 2:}

\section{Trout movement within a restored Appalachian watershed}

The warming of headwater streams due to climate change has been identified as a potential cause for the decline in suitable coldwater habitat for fish species on a global scale (Rahel et al. 1996, Nakano et al. 1996, Buisson et al. 2008, LaSalle \& Rochard 2008, Yu et al. 2013). Additionally, historic anthropogenic activities in watersheds have had a wide array of long-term effects on fluvial systems and freshwater biota around the world (Li et al. 2011, Harden, 2006). Human activity has therefore led to pervasive and large-scale environmental change (Nilsson et al. 2005) and the fragmentation of available coldwater stream habitats in the Appalachian mountain region.

This fragmentation can degrade aquatic habitat at both localized and watershed scales. However, many habitat restoration efforts are primarily targeted at specific sections or 'reaches' of a stream system. It is therefore important that scientists and managers additionally examine and work to maintain suitable fish habitat at a larger spatial grain and the riverscape scale. Operating at these broader scales allows for inferences into habitat suitability and connectivity in a riverscape context- including genetic diversity and metapopulation dispersal between disparate complementary (i.e., spawning) and supplementary (i.e., foraging) habitats and thermal refugia.

The improvement of physical habitat in historically impacted watersheds, riparian corridors and stream channels has been a fundamental aspect of coldwater fisheries management in the North America for decades (Hunt 1976, Riley \& Fausch 1995, Massey 2016). Habitat restoration projects represent a significant investment of both financial and human capital for resource agencies and biologists in the United States (Roni 2005). Therefore, it is critical that we both identify the best candidate high-elevation streams for targeted 
restoration activities (those most resilient to human activity and climate change), and understand the relationship between aquatic organisms and habitat improvement efforts undertaken within those systems (Shepard et al. 2016).

Although efforts to restore and improve stream habitats are generally increasing in the United States, assessments of the ecological response of individual organisms to these efforts are generally lacking. This is particularly true with respect to the movement of organisms among complementary and supplementary habitats in response to a restoration event. Such assessments of animal response to restoration will be crucial both to identifying candidate streams for restoration and maximizing the effectiveness of restoration projects within those systems.

This is particularly true for managing native Brook Trout Salvelinus fontinalis in Appalachian streams. In the Appalachian Mountain region, many of the high-elevation, coldwater stream systems have been historically degraded by logging and loss of canopy cover, increasing sediment load and turbidity, acid mine drainage (AMD) and general loss of instream habitat (Meehan 1991). In many cases, culvert construction for roads and railroads in headwater systems has created an unnatural segmentation of mainstem rivers from their tributaries.

The construction of culverts has also led to the genetic isolation of fish populations, and has an established positive relationship to fine sediment accumulation and embeddedness in stream systems. The construction of road culverts can therefore have a direct and negative impact on Brook Trout populations (Eaglin et al 1993). Increasing water turbidity, which is often associated with fine sediment accumulation, can also have a negative effect on Brook Trout foraging success and growth (Sweka \& Hartman 2001). This means that road culverts and their associated sedimentation can have a twofold impact on Appalachian Brook Trout. 
Competition with non-native salmonids can additionally force native fish out of otherwise suitable habitat, with wild Brown Trout Salmo trutta and stocked Rainbow Trout Oncorhynchus mykiss often outcompeting native Brook Trout for limited food resources and thermal refugia (Larson \& Moore 1985, Myers et al. 2014, Hitt et al. 2016). These impacts represent a multifaceted and extensive pressure on native Brook Trout in the eastern United States. Recent studies assert that Brook Trout have been extirpated from more than one quarter of their historic range, and predict further range reductions in the near future (Hudy et al. 2008).

Due to the spatiotemporal nature of environmental stressors and food resources in lotic systems, the ability of fishes to respond to environmental change and move between habitats is of paramount importance on both an individual and population-wide scale (Petty et al. 2012). Movement was once thought to be a small factor in the life history of stream fishes, as it was believed most individuals were largely sedentary with limited long-range movements to accomplish spawning migrations (Gerking, 1953, 1959). Research by Bachman (1984) lead to widespread acceptance of the belief that most stream fish exhibited 'restricted movement'.

Continued research has since led biologists to understand movement as a much more important aspect of the life history of freshwater fishes, allowing them to maximize limited trophic resources, occupy preferential thermal habitats and complete necessary linkages between stages of their life history (Rahel et al.1996, Rodriguez 2002, Goniea et al. 2006). In many cases, fish populations are comprised of both sedentary and highly mobile individuals (Petty et al. 2012). Additionally, fish movement is most often observed as a discrete event, rather than a prolonged behavior (Petty \& Grossman 2004).

One method to assess the ecological suitability and physical connectivity of fluvial environments is to observe the movement of fish throughout them (Roghair 2005). As mobile, habitat selective residents of coldwater Appalachian streams, Brook Trout and Brown Trout movements represent effective metrics for such assessment (Young 1996, Roghair 2005). 
Indeed, habitat use and the aquatic environment niches occupied by salmonids are the focus of studies by fisheries biologists across a host of geographic locales and highly variable watersheds (Nickelson \& Rodgers 1992, Rousell et al. 2004, Roper \& Scarnecchia 1994).

The migration of trout species into coldwater tributaries as thermal refugia is also of interest to those concerned with watershed-scale management of native fish species (Kaeding, 1996, Young 1996). The use of intermittent floodplain tributaries is another important factor to consider when evaluating the movement of fish in a headwater system (Wigington et al. 2006, Hartman 1987). Such inquiry into the movement of trout in high-elevation streams can additionally serve to improve our understanding of the interaction that aquatic wildlife has not only with habitat improvement and climate change mitigation efforts, but also naturally occurring variables such as flow patterns, water temperature and tributary connectivity (Petty et al. 2012).

The use of radio telemetry surveys has become commonplace in the field of fisheries management, particularly regarding the assessment of salmonid movement and migratory fish surveys (Gowan \& Fausch 1996, Metcalfe \& Arnold 1997). While movement studies of adult Rainbow Trout and Brown Trout are fairly common, Brook Trout, particularly small $(<20 \mathrm{~cm})$ individuals, have largely been omitted from past research for a handful of reasons. First, the nature of surgical implantation of radio tags necessarily limits the candidate size of the given sample population to those large enough to survive anaesthetization and surgery (Cooke et al. 2011). Second, small individual fish have historically been thought of to exhibit limited movement habits, limiting the value of prospective inquiry (Adams et al. 1998). Advances in telemetry technology (namely detection range and battery life) have also been necessary to increase the practicality of tracking fish movement in an open stream habitat. Additionally, relatively few intact populations of native Brook Trout remain throughout their historic natal range, limiting potential study subjects in this direction of research. 
By actively tracking the movement of adult trout in Appalachian watersheds, it is hoped that we can gain an understanding of both native (Brook Trout) and non-native (Brown Trout) species' response to environmental conditions such as habitat connectivity, flow regimes and thermal refuge. A prime objective of this study is to quantify the movement and habitat selection of individual fish following a restoration event. It is an additional goal of this research to add to the growing body of research on salmonid movement in a riverscape context. Through this process, it is possible that we may also assess the effectiveness of restoration efforts, and better direct management initiatives to protect Appalachian Brook Trout and their habitat throughout their historic range.

Given the mobile lifestyle of many Brook Trout and the management efforts focused on improving habitat throughout their native range, it is a logical step to compare the movement patterns of Brook Trout in restored watersheds against available pre-restoration data. It would additionally be prudent to examine the efficacy of different habitat restoration techniques by observing the response of movement in individual fish to varieties of physical habitat alteration (in-stream structures, tributary reconnection and water treatment). Each of these management tools has been applied in a particular high-elevation stream system located in the Appalachian Mountains of eastern West Virginia with a history of human influence, providing an exemplary site for the study of fish in pre- and post-restoration habitats.

The objectives of the current study are to 1) quantify Brook and Brown Trout movement and habitat use throughout a high-elevation watershed consisting of a restored mainstem stream channel and reconnected tributaries, comparing these results to a pre-restoration study; and 2) determine association of native and exotic trout with restored habitat structures on the mainstem channel. The overall goal of this research is to examine the relationship between native and exotic fish communities and physical habitat restoration activities undertaken in a coldwater Appalachian stream system. 


\section{STUDY AREA}

The upper Shaver's Fork is a large (basin area $>150 \mathrm{~km}^{2}$ ) headwater system located largely in the Monongahela National Forest of the central Appalachian Mountains, with land cover dominated by mixed deciduous-coniferous forest (Figure 1). The Shaver's Fork is one of three major tributaries of the Cheat River drainage basin, flowing northward towards its confluence with the Blackwater River and Dry Fork near the town of Parsons, WV. Natural variation in the physical size and fluvial geology of the stream lead to a high degree of variability in habitat characteristics and water chemistry in this watershed (Petty et al. 2005, Petty \& Thorne 2005). Significant anthropogenic alterations to the headwaters of Shaver's Fork began in the late $19^{\text {th }}$ and early $20^{\text {th }}$ century, with extensive coal mining activity and clear-cutting of red spruce Picea rubens forests. The extensive logging activity in the area, coupled with the development of the railroad along the length of the stream radically altered the characteristics of the watershed. The removal of trees in the riparian zone and the laying of a railroad corridor acted to widen and shallow the main-stem channel, while simultaneously severing Brook Trout access to tributary networks and spawning habitat (Petty et al. 2005, Poplar-Jeffers et al. 2009).

This direct warming influence on local stream temperatures, along with the fragmentation of thermal habitat and loss of riparian shade zones had wide-reaching implications for resident fish communities. The human history of this region and the general climatic warming trend in stream temperatures in the eastern United States comprise a multifaceted threat to the restoration and management of resident native Brook Trout populations (Eaton \& Scheller 1996, Habera \& Moore, 2005). The development of Marcellus shale resources in and around the Monongahela National Forest presents newly relevant factors in the management and improvement of Brook Trout habitat in Shaver's Fork and other high-elevation Appalachian stream habitats (Weltman \& Taylor 2013). 
To mitigate the pervasive effects of global climate change as well as the localized impact of historic human activity in the area, several habitat improvement projects have been undertaken on Shaver's Fork by the West Virginia Department of Natural Resources (WVDNR). The major goals of this project included a general narrowing and deepening of certain areas of the mainstem channel, as well as increasing Brook Trout access to thermal refugia and formerly severed tributary systems. These projects involved the construction of single and double-wing flow 'deflectors', cross-vane 'J-hook' structures and Large Woody Debris (LWD) implantation in targeted segments of the channel. These measures are directed towards the creation of 'structure pools' which are to serve as thermal refuge for Brook Trout (Bennett 2012).

Additionally, three tributary streams historically severed by the railroad (Beaver Creek, Lamothe Hollow and Oats Run) were targeted for culvert-removal projects and were reconnected with the mainstem using passage-friendly culverts. WVDNR proposed that increasing the availability of cold-water habitat on the main stem and restoring connectivity to second-order tributaries would reduce seasonal thermal stress on Brook Trout in the watershed. Given the history of human activity and development on upper Shaver's Fork, its location in the south-central reaches of the historic natal range of Brook Trout, and the remote high-elevation nature of the watershed, this stream lends itself particularly well to the analysis of coldwater native species protection and restoration efforts in the face of climate change. 


\section{METHODS}

In order to provide a reference context for fish movement in this particular stream habitat, a previous study completed by West Virginia University (Hansbarger, et al. 2008, Petty et al. 2012) was utilized. In that study, Brook and Brown Trout on Shaver's Fork were tagged and tracked via radio telemetry throughout the mainstem of Shaver's Fork as well as a secondorder tributary known as Rocky Run. The results of this study showed a very limited movement of Brook Trout tagged in Rocky Run, while fish tagged on the mainstem of Shaver's Fork showed a varied amount of movement. This data provides valuable insight into the dynamics of fish movement and spatial ecology of trout in a pre-restoration stream system. To track the movement of fish throughout Shaver's Fork and assess the interaction of Brook and Brown Trout with restoration efforts, a study group totaling 51 Brook Trout (23 in 2015 and 28 in 2016) and 13 Brown Trout (5 in 2015 and 8 in 2016) were captured and implanted with radio telemetry transmitters during the weeks of June 3-5, 2015 and May 31 - June 3, 2016.

\section{$\underline{\text { Trout Capture and Tagging }}$}

Fish used in this study were captured in the upper $11 \mathrm{~km}$ of the Shaver's Fork mainstem (Figure 1) via backpack electrofishing techniques using Smith-Root LR-24 DC Electroshockers. Once captured, fish were held inside in-stream livewells until beginning the tagging procedure. Livewells were constructed from 30 -gallon plastic storage containers with $1 / 4$ inch holes drilled throughout the bottom $20 \mathrm{~cm}$ of the container to enable the continuous circulation of stream water. Livewells were placed in shaded areas with high surface flow; in areas lacking abundant canopy cover livewells were covered to ensure a cool, shaded recovery area. 
After capture, fish were held in livewells in groups of up to six fish to recover from electrofishing trauma and await anesthesia and surgery. Individual fish were removed from the recovery livewell and held in a closed, CO2-rich container until they entered an observable state of narcosis, allowing for the tagging procedure to begin. Throughout all steps of the tagging surgery, all trout were handled according to the guidelines of the West Virginia University Animal Care and Use Committee (Protocol Number 11-0507).

Upon anesthesia, fish were placed on a specialized surgery table (Courtois 1981) and internally implanted with their transmitter tags through a surgical procedure known as the 'Shielded Needle Technique' (Ross \& Kleiner 1982), a commonly used method in internal tagging applications for salmonids (Jepsen et al. 2002). Procedures and methodology were adopted from several previous telemetry surveys of fish movement (Winter 1983, Swanberg 2011, Jepsen et al. 2002; Petty 2012). First, all surgical instruments (including tags) were sterilized using an iodine solution bath. A 1-cm incision was made on the ventral side of the fish between the pectoral and pelvic fins. A second 'port' was created posterior to the initial incision using a 16-gauge catheter needle, through which the transmitter antennae was threaded, oriented facing the posterior of the fish.

A small $(1.1 \mathrm{~g})$ radio transmitter tag (Lotek model NTQ-3-2) was then inserted into the primary incision, the catheter was then used to pull the tag's 6 -inch antenna through the posterior port. The incision was then stitched closed using size 3-0 and 4-0 Monocryl nonabsorbable sutures, each fish required no more than two complete stitches, and in the case of most Brook Trout, a single stitch properly closed the incision. This procedure eliminates the risk of the transmitter antenna protruding through and interfering with the primary incision. Throughout the tagging procedure, the fish's gills were irrigated using a small turkey baster containing stream water, with the goal being a recovery from anesthesia closely timed with completion of the surgical procedure. 
The smallest transmitters practical to the length of the survey were selected to comply with the 'modified Winter Rule', which asserts $2.5 \%$ of fish body weight as the maximum transmitter weight- using heavier transmitters could potentially interfere with the swimming ability of the fish (Winter, 1983). I limited tagging to fish larger than 44 grams, or about 150mm.

After surgery, fish were allowed to recover in shaded in-stream livewells and then released as close to the point of capture as possible. Some fish were held to ensure that they were able to recover from the stress and capture of surgery, but no fish were held for a period of over 24 hours. In general, fish recovered quickly ( $<5$ minutes) after surgical procedures. Two Brown Trout from the 2016 study group were recorded as surgery mortalities, and represent the only known post-surgical mortalities within the study group throughout either the 2015 and 2016 field seasons.

\section{$\underline{\text { Trout Tracking and Movement }}$}

Tracking fish was accomplished by using a Lotek radio telemetry receiver (Model SRX $600)$ to detect individually coded tags on different frequencies for the $2015(149.420 \mathrm{MHz})$ and 2016 (150.530 MHz) field seasons. Tagged fish were tracked throughout the uppermost $25 \mathrm{~km}$ of Shaver's Fork and its tributaries during their respective field seasons over a period of 70-75 days. Tracks were begun at variable times of day and locations each session to limit the influence of diel movement in fish.

Tracking was initiated each season ten days after the tagging surgeries were completed, to allow for full recovery and resumption of normal movement behavior (Petty et al. 2012). Tracks of the entire mainstem study section were made at least once a week during the tracking season. Major tributary systems were walked at least three times throughout the field season. All located intermittent and unmapped tributaries in the study section were surveyed at least 
once, and intermittent tributaries where fish were tracked were surveyed regularly throughout the field season. Due to their proximity to the mainstem and relatively limited stream length, tracks of intermittent tributaries were more easily included into tracks of the mainstem channel. However, due to the relatively large nature of the study section and the inherent complexities of watershed systems, it is impossible to verify if all intermittent tributary systems were surveyed. Every effort was made to acquire visual confirmation of the fish's location, but this was not always possible due to water depth and other habitat complexities such as undercut banks, large boulders and turbidity.

Due to the strength of signal detection (100-250m) and the relatively narrow physical nature of the mainstem channel and second-order tributaries (1-25m wetted width), it is unlikely any fish were unaccounted for in sections which were surveyed. Fish which were not resolved by radio telemetry tracking (i.e. fish that were never found after tagging) are most likely due to removal from the study section due to predation, angler harvest, or movement outside of the surveyed section. Extensive effort was devoted to limiting the loss of fish from the study group due to normal movement behaviors (i.e. tracks were extended $>5 \mathrm{~km}$ downstream from the lowest tagging site of Beaver Creek, all locatable tributaries were surveyed to the extreme headwaters, etc.).

At the resolution of each individual track, habitat and substrate observations were recorded for each individually observed fish location. Hydraulic Channel Units (HCUs) were separated into classes previously described in upper Shavers Fork, natural pools (NAT POOL), riffles (RIF), runs (RUN), and structure pools (STR POOL) (Petty et al. 2003). We also described the average substrate composition- substrate was classified into one of five categories as defined by the ISO 14688-1:2002 International Scale: bedrocks (embedded rock surface), boulder (200-1000mm), cobble (63-200m), gravel (2-63mm) and sand $(<2 \mathrm{~mm})$. 
Movement metrics collected from this study include total movement $(\mathrm{m})$, a measure of a fish's total distance moved from its tagging site. Total movement rate indicates the distance moved as a function of time. In this instance, 'time' is defined as the 'Days at Large', or number of days from the first resolved track to the last resolved track. Therefore, the total movement rate is best described as the amount a fish moved over the period it was surveyed in this study.

\section{Statistical Analyses}

Our first objective was to quantify watershed-scale Brook and Brown Trout movement throughout the study area, and to compare that data with a pre-restoration study. We first calculated total movement as the total distance moved between successive tracks over the study period by each fish. Because movement distance has been shown to be correlated with days at large, we calculated total movement rates (=total movement/total days at large). We also calculated total dispersal and dispersal rate. Dispersal metrics differ from movement in that dispersal indicates net upstream or downstream movement from the tagging site, with negative dispersal values indicated a net downstream movement from the tagging site and positive values indicating a net upstream movement. To complete this analyses, the first task was to establish any directional movement or dispersal pattern observed in tagged Brook Trout. A twotailed t-test was run on dispersal metrics for both the 2015 and 2016 field seasons, comparing dispersal tendency to 0 . The null hypothesis was that there was no directional movement pattern in either the 2015 or 2016 field season.

Finally, in order to characterize movement within and among mainstem and tributary habitats, total movement was separated into three segments: (1) Mainstem Movement- a fish's total recorded movement from tagging site to either the mouth of a tributary or the final tracking location in the case of a fish remaining in the mainstem channel, (2) Up-Tributary Movement: a 
metric of distance from the junction of a tributary with the mainstem channel to the first resolved track of a fish in a tributary, and (3) Intra-Tributary Dispersal- a metric of total movement (up or downstream) of a fish from the first established tracking location in a tributary to the final established tracking location. Similar to the primary analysis of directional movement, a comparison of mainstem versus tributary movement in Brook Trout for both field seasons was established using two tailed T-tests. A comparison of dispersal between species and years was also completed via a two-way ANOVA accounting for both Brook and Brown Trout in the 2015 and 2016 field seasons.

To facilitate a comparison of post-versus pre-restoration fish movement, a prior survey of Brook and Brown Trout movement on Shaver's Fork (Petty et al. 2012) was used as a reference. By comparing the movement and dispersal data resulting from the current study with the data collected in the pre-restoration survey of Shaver's Fork, we hope to describe the ecological response of native and exotic aquatic organisms to physical habitat restoration activities. Brook Trout from the pre-restoration survey which were tagged in tributaries were omitted from these analyses due to the seasonal and locational statistical bias. Additionally, fish smaller than those tagged in the pre-restoration study ( $<72$ grams) were omitted from analysis to block the effect that size may have in analyzing the response of Brook Trout to habitat structures.

Comparing Brook Trout movement and dispersal metrics between size classes of fish could be a practical means of explaining differences seen between the pre-restoration and postrestoration studies. To accomplish this comparison, fish in the 2015 and 2016 field seasons were separated into two size classes by weight. Since the pre-restoration survey had a lower size limit of 72 grams, fish in the post restoration study were separated into either a 'small' (50$72 \mathrm{~g})$ and 'large' (72-205g) size class. This was done to examine the influence of including smaller fish in this survey versus the pre-restoration movement study. Data from both studies of 
fish movement were analyzed using Kolmogorov-Smirnov tests to check for differences in movement and dispersal of both Brook and Brown Trout post-restoration. Additionally, two tailed T-tests were applied to total dispersal metrics of comparably sized fish from both of the movement studies.

Our second objective was to determine the association of native Brook Trout and exotic Brown Trout with restoration activities undertaken in the mainstem of Shaver's Fork. To accomplish this, fish locations were separated binarily into restored versus non-restored sections. All structure pools and constructed habitat features on the mainstem channel were described as 'restored sections'. Although fish moving into reconnected tributaries were quantified as part of this study, these fish were excluded from this particular analysis. Data on Brook and Brown Trout association with habitat structures was then analyzed via Fisher's exact tests comparing HCU use among years and among both species within years.

Additionally, data from a USGS streamflow gauge was used to compare discharge in the watershed pre- versus post-restoration. This station was only operable beginning in the winter of 2000 , so only comparisons from the second summer of the pre-restoration study were available for comparison to the post-restoration study. Streamflow was compared using Kolmogorov-Smirnov tests for significance for the periods of June 5 - August 15 2001, 2015 \& 2016. 


\section{$\underline{\text { RESULTS }}$}

\section{Quantifying Trout Movement}

There was no significant difference in total dispersal $(t=1.69 p=0.257)$ or movement rates $(t=2.05, p=0.599)$ of Brook Trout when comparing metrics between the 2015 and 2016 tagging groups (Tables 1 \& 2). Brook Trout in 2015 had an average total movement of $3.31 \mathrm{~km}$ $($ range $=120-8210 \mathrm{~m})($ Figure 2$)$, with an average movement rate of $60.86 \mathrm{~m} /$ day (Figure 3 ). The mean distance moved by Brook Trout in the 2016 field season was $2.86 \mathrm{~km}$ (range $=220$ $11304 \mathrm{~m}$ ) (Figure 4), with an average movement rate of $50.02 \mathrm{~m} /$ day (Figure 5).

Observations of net dispersal in Brook Trout between field seasons show a net downstream movement trend in the 2015 field season (mean dispersal = -956 m), while Brook Trout in the 2016 season exhibited a net trend of upstream movement (mean dispersal $=572$ m). Despite these yearly directional tendencies, Brook Trout did not exhibit significant directional movement in either $2015(\mathrm{t}=0.53, p=0.367)$ or $2016(\mathrm{t}=0.69, p=0.499)$. This indicates that there was no statistically significant up- or downstream directional tendency in movement of Brook Trout tagged in either the 2015 of 2016 field season. T-tests of the same null hypothesis for Brown Trout indicate no directional movement tendency in fish tagged in either the $2015(p=0.21)$ or $2016(p=0.24)$ field season.

Two-way ANOVAs were completed on movement metrics by fish species and year. The first analysis was run on log-transformed movement rates (meters/day), with a result $(F=4.57$, $p=0.038$ ) that indicates a verifiable difference between movement rates of Brook and Brown trout tagged in this study. Brook Trout moved an average of $50.51 \mathrm{~m} / \mathrm{d}$ in 2015, whereas Brown Trout in 2015 moved an average of $28.19 \mathrm{~m} / \mathrm{d}$. Brook Trout tagged in 2016 had an average movement rate of $50.02 \mathrm{~m} / \mathrm{d}$, compared to an average movement rate of 17.22 for Brown Trout in 2016. While movement rate varied significantly between species, there was no verifiable 
effect on movement as a function of year $(p=0.217)$, indicating similar dispersal rates in fish for both the 2015 and 2016 field season.

Brook Trout which did not leave the mainstem exhibited significantly lower total movement than fish which moved into the tributaries $(p<0.001)$. Additionally, Brook Trout which remained in the mainstem exhibited lower average rates of movement $(30.6 \mathrm{~m} / \mathrm{d})$ than fish which moved into tributaries $(61.75 \mathrm{~m} / \mathrm{d})$ across both the 2015 and 2016 field season. Although all fish in this survey were tagged and released on the mainstem of Shaver's Fork, this study has similar results to the pre-restoration study- with fish on the mainstem and in intermittent tributaries exhibiting significantly lower movement rates than those in larger tributary systems in both the $2015(t=1.4, p=0.09)$ and 2016 field seasons $(t=2.1, p=0.004)$.

Two-way ANOVAs were also run on metrics of total mainstem movement versus total tributary movement of Brook Trout by year. Only fish which moved into tributaries were used for comparative analysis of mainstem versus tributary movement in individual fish. Results of this analysis indicate statistically significant differences in total movement metrics for mainstem $(2015$ mean $=1.97 \mathrm{~km}, 2016$ mean $=1.77 \mathrm{~km})$ versus tributary $(2015$ mean $=1.12 \mathrm{~km}, 2016$ mean $=1.08 \mathrm{~km})$ movement in individual Brook Trout $(F=8.69, p=0.007)$. The second focus of this analysis found tagging year (2015 or 2016) did not represent a significant influence on total movement metrics for fish in either field season $(F=1.03, p=0.32)$.

The 23 Brook Trout tagged in the 2015 field season exhibited variable movement and dispersal patterns. Seven Brook Trout were not resolved with telemetry tracks, and were not located after tagging surgery. Brook Trout displayed extensive movement up and down the mainstem channel of Shaver's Fork into extreme headwater habitats of second-order tributary systems, with the highest recorded total movement of $8.2 \mathrm{~km}$, of which $6.1 \mathrm{~km}$ was down the mainstem channel. The four Brook Trout located in the mainstem channel had a mean total recorded movement of only $1.3 \mathrm{~km}$. 
Once Brook Trout had displayed extensive movement throughout the mainstem channel and upstream into headwater tributary habitats, there was little continued movement throughout the field season. The average Intra-Tributary Dispersal for Brook Trout in the 2015 field season was just 167 meters, compared with an average of 2km Mainstem Movement and an average of $1.2 \mathrm{~km}$ Up-Tributary Movement to the first resolved tracking location. Fish consistently underwent extensive movement into headwater tributaries, and then moved very little throughout the duration of the field season. The results on intra-tributary movement of Brook Trout from this study are consistent with those from the previous study. Brook Trout in tributaries of Shavers Fork exhibited very little movement upon reaching headwater habitats. The previous survey found significantly greater rates of movement in mainstem Brook Trout versus fish which were tagged in the tributaries.

Brown Trout in the 2015 field season showed very limited movement in comparison with Brook Trout. Of five tagged Brown Trout, four were resolved with tracks and remained in the mainstem channel throughout the duration of the study. No Brown Trout were tracked moving into tributary systems at any point in the field season. Because of this, Brown Trout Total movement was not separated into the three distinctions used for Brook Trout. Brown Trout on the mainstem channel averaged just $1.2 \mathrm{~km}$ of total movement, three of four tracked fish had recorded total movements of less than 900 meters. Brown Trout exhibited strong site fidelity to the mainstem structure pools constructed on Shaver's Fork. Two of the four Brown Trout tracked remained in structure pool habitats throughout the duration of the field season.

Brook Trout demonstrated significant dispersal both up and downstream (Table 1). In many cases, fish moved down the mainstem channel from the tagging site, and then moved into intermittent and second-order tributary systems. Upon entering the tributaries and occupying specific hydraulic channel units, Brook Trout then displayed very little intra-tributary movement, often remaining in distinct hydraulic channel units ( $\mathrm{HCU})$ for several weeks. Brook Trout in the 
2015 field season exhibited a mean dispersal downstream from their tagging sites (net dispersal $=-956 \mathrm{~m}$ ). It must be noted that in many instances, these fish moved downstream from their tagging site, and then several kilometers up tributary systems, giving a negative dispersal value even though the vast majority of movement had been upstream in a second-order tributary.

Fish moving down the mainstem from their tagging site averaged a net up-tributary movement of $1.75 \mathrm{~km} \mathrm{(2015)} \mathrm{and} 2.64 \mathrm{~km}$ (2016), all of which contributes toward a net downstream dispersal bias, even though there is evidence of extensive up-tributary movement.

Brown Trout in the 2015 field season engaged in relatively little directional movement (Table 1), with some individual fish exhibiting total locational movement of less than $0.5 \mathrm{~km}$ over two months. On average, Brown Trout in the 2015 season dispersed slightly upstream from the tagging site- of all four Brown Trout with resolved tracks, only one exhibited directional movement totaling more than $1 \mathrm{~km}$. The fish SATR_1 moved a total of $2.98 \mathrm{~km}$ entirely in the mainstem channel, representing the only large directional movement of a Brown Trout in the 2015 tagging season. This fish resided in a single structure pool on the mainstem channel throughout the entire 2015 season. Interestingly, this fish would be recaptured and retagged as SATR_ 5 in the 2016 field season- the only fish retagged throughout the duration of this study.

Of the 28 Brook Trout tagged in the 2016 field season, 23 were resolved with locational tracks, again displaying a variety of movement behaviors and a wide array of habitat selection. Fourteen Brook Trout moved into major second order tributary systems, again representing the largest class among major tributary, intermittent tributary and mainstem fish groups. Four fish moved into intermittent and floodplain tributary systems, and similar to the 2015 field season, these streams at times separated from the mainstem channel. Five Brook Trout remained on the mainstem of Shaver's Fork, and again associated largely with natural thermal refugia and major coldwater sources. Five fish were not resolved with repeated telemetry tracks, and were not located after initiating tracking surveys. 
Similar to the previous field season, Brook Trout displayed large-scale dispersal and movement up and down the mainstem channel into a variety of tributary habitats. The highest recorded Total movement of a Brook Trout in the 2016 field season was $11.3 \mathrm{~km}$, comprised of over $6 \mathrm{~km}$ of movement down the mainstem channel and $5 \mathrm{~km}$ of movement up the major tributary of Second Fork. On the other hand, and again like the 2015 field season, Brook Trout residing on the mainstem of Shaver's Fork and in intermittent tributary systems exhibited much more limited movement throughout the survey.

The five Brook Trout remaining on the mainstem channel had a mean total movement of 804 meters. Mainstem fish again associated with natural thermal refugia, and again no Brook Trout were tracked in constructed pool habitats throughout the 2016 field season. Two fish (SAFO_36 and SAFO_44) were located in the reconnected tributary system of Lamothe Hollow and remained in that tributary throughout the field season. One fish (SAFO_25) resided in the mainstem channel of Shaver's Fork at the inflow of the reconnected tributary Beaver Creek for most of the field season, and was tracked within the lower reaches of Beaver Creek shortly before the end of the field season. These three fish necessarily interacted with the improvedaccess culvert systems constructed to facilitate tributary use by Brook Trout on Shaver's Fork.

The segmentation of movement patterns between mainstem, up-tributary and intratributary provided results similar to the 2015 field season: in most cases Brook Trout underwent extensive long-range movements into headwater tributary networks, and upon reaching these habitats, exhibited very limited movement throughout the duration of the survey season. Average Brook Trout Mainstem Movement in the 2016 field season was $1.77 \mathrm{~km}$. Average uptributary movement was $1.35 \mathrm{~km}$. Intra-tributary dispersal was again very limited, with $115 \mathrm{~m}$ being the average of all tributary fish.

Eight Brown Trout were tagged in the 2016 field season, and five were resolved with repeated tracks on the mainstem channel. Two Brown Trout were recorded as surgery 
mortalities, as they were found dead in the stream channel shortly after the initiation of tracking surgeries. Of the five resolved tracks, three fish occupied constructed pool habitats on the mainstem channel, and the remaining two occupied natural deep bluff pools. No Brown Trout were observed in any tributary system at any time during tracking surveys. Average Brown Trout total movement was just $1.15 \mathrm{~km}$, with an average Movement Rate of $17.22 \mathrm{~m} /$ day. Brown Trout tagged in the 2016 field season showed strong site fidelity to thermal refugia on the mainstem channel of Shaver's Fork, both constructed and natural.

The movement of Brook Trout in the 2016 field season shows a number of differences from the previous summer. First, dispersal upstream from tagging site (net dispersal $=572 \mathrm{~m}$, Table 2), differed from the previous year- where although fish moved extensively into tributaries, their directional movement patterns tended towards downstream movement from the tagging site. Additionally, fish engaged in a broader range of movement- including individual fish travelling over $9.4 \mathrm{~km}$ - the highest value recorded in either field season. Lastly, while individual Brook Trout demonstrated higher maximum movement totals in 2016 compared to the 2015 field season, the overall mean total movement for Brook Trout was lower in 2016 (2,862 m) versus the 2015 field season (3,308 m). The study group of Brook Trout was significantly larger in 2016 (23 fish) versus 2015 (16 fish), perhaps leading to the extreme high values of movement observed in the 2016 field season to be less influential when included with a larger sample of movement rates.

Analyses of environmental variables in the upper Shaver's Fork watershed comparing the pre- and post-restoration periods showed variable results by season (Figures $6 \& 7$ ). The 2015 season had higher average streamflow (200.1 cf/s) than either the $2016(100.6 \mathrm{cf} / \mathrm{s})$ or 2001 (152.6 cf/s) field seasons. However, there was no statistically significant difference in mean stream flow between the 2015 and 2001 field seasons $(D=0.194, p=0.131)$. There was a significant difference between streamflow in the summers of 2016 and 2001 ( $D=0.375, p<$ 
0.001). Additionally, there was a significantly higher average streamflow in the 2015 field season than in the 2016 field season ( $D=0.315, p=0<0.001)$.

The Shavers Fork watershed was subject to intense flooding the week of June 23, 2016 (Figure 7). This extreme streamflow event was the most pronounced period of rainfall in either of the two field seasons. This flooding changed in-stream habitat by moving substrate and leading to a massive influx of LWD. This flooding occurred shortly after the initiation of tracking for the 2016 field season, and while it appears Brown Trout largely remained in mainstem pool habitats, Brook Trout in many cases had moved into intermittent tributary systems. Few Brook Trout in the 2016 season were tracked in the mainstem channel prior to this flood event, so it is not possible to infer that this rainfall was the causal mechanism for their dispersive mobility.

A single retagged Brown Trout (SATR_1\&SATR_5) demonstrated a strikingly similar movement pattern in both years of this study (Figure 8). This fish was captured in nearly the exact same location each field season, and exhibited a very similar total movement value $(3,180 \mathrm{~m}$ in 2016 and $2,980 \mathrm{~m}$ in 2015). Additionally, this fish was continually observed residing in the same mainstem habitat structure pool in both survey years. This retagged fish gives an interesting insight into the year-to-year movement patterns observed in large resident Brown Trout in the Shavers Fork system. The fish SATR_1/SATR_5 demonstrated nearly the exact same movement pattern from year to year, occupying the same pool throughout seasonal variations in environmental conditions.

\section{Comparing post versus pre-restoration}

To complete the first objective and compare movement of fish in a post-versus prerestoration framework, we attempted to identify the movement response of fish to physical habitat restoration undertaken on Shaver's Fork. When comparing dispersal metrics for Brook 
Trout of sizes consistent with the previous study (72-205 grams), the results are variable. There was a statistically significant difference in dispersal for Brook Trout from both the 2015 and 2016 field seasons compared to those tagged in the pre-restoration survey (Kolmogorov-Smirnov test statistic $D=0.35, p=0.02$ ). When separating the study group by year, the analyses begin to show slight differences. The 2015 tagging group shows a statistically significant difference in dispersal rate $(D=0.458, p=0.05)$ from the pre-restoration tagging group. However, Brook Trout tagged in 2016 did not show such a difference from the pre-restoration survey $(D=0.406$, $p=0.095)$. When comparing dispersal metrics for Brown Trout pre-versus post-restoration, there is a strongly significant difference $(D=1.0, p<0.001)$. This points towards a response in in fish movement to the physical habitat construction on Shaver's Fork (Figures $9 \& 10$ ).

In comparison to the Brook Trout, Brown Trout engaged in very limited movement and low dispersal rates in both the 2015 (Figure 11) and 2016 (Figure 12) field seasons, with each fish remaining in the mainstem (Figures 13 \& 14). Brown Trout associated closely with thermal refugia, including the habitat structures designed during the restoration effort intended to improve Brook Trout habitat on Shaver's Fork. This is an unexpected observation- that habitat improvement efforts directed at native fish populations may have had an unintended benefit for exotic species in the system. In the few cases of Brook Trout being found on the mainstem, none were repeatedly observed in mainstem habitat structure pools. In the 2015 field season, there was no observation of any tagged fish in the reconnected tributary systems of Beaver Creek, Lamothe Hollow or Oats Run (Figures 15 \& 16). However, in 2016 one Brook Trout was observed moving into Beaver Creek and two Brook Trout were tracked to the upper reaches of Lamothe Hollow (Figure 17). 


\section{Determining Trout Association with Habitat Structures}

The second objective of this study was to determine the association of native and exotic trout with restored habitat structures on the mainstem channel. A Chi-squared goodness of fit test was applied to habitat structure association data which consisted of binary values describing locational relationship with mainstem habitat features. This test indicates that there is a statistically significant relationship between Brown Trout and constructed habitat on Shaver's Fork $\left(X^{2}=14.24, p<0.001\right)$. Similar analyses for relationship between Brook Trout and habitat structures show no significant result $\left(X^{2}=38.86, p=0.651\right)$ in either the 2015 or 2016 field season. Additional tests on total net movement of fish in relationship to habitat features shows no verifiable response $\left(X^{2}=43.43, p=0.581\right)$. Locational tracks also provided very little evidence of Brook Trout using constructed pool habitats on the mainstem channel.

Hydraulic channel unit use by Brook Trout varied between the 2015 and 2016 field seasons (Figures 18,19,20 \& 21). Analyses were limited to three habitat observations which were then randomized, in order to avoid bias toward repeated tracks in the same channel unit. Comparisons were made on percentage of observations to avoid bias in number of fish tagged each year. Brook Trout were observed using riffle habitats in greater proportions in the 2016 tracking season versus 2015. This study provided observations of generally higher use of riffle habitats by Brook Trout than pool habitats in both years- something uncharacteristic to Brook Trout movement studies. In very few cases were Brook Trout tracked to habitat structure pools on the mainstem channel. In both field seasons, Brown Trout readily and preferentially occupied mainstem habitat structure pools. It appears from these observations that Brown Trout frequently utilize the structure pools designed to provide thermal refuge for native Brook Trout on the mainstem of Shavers Fork. 


\section{DISCUSSION}

Our results suggest that native (Brook Trout) and non-native (Brown Trout) species are responding to watershed-scale restoration activities undertaken with the upper Shaver's Fork watershed. Specifically, Brook Trout changed their movement patterns following restoration to exhibit higher rates of movement and greater total dispersal (Figures 13 \& 14). Although Brook Trout never specifically associated with habitat restoration activities on the mainstem, they were observed dispersing into previously severed tributary networks which had been reconnected as part of the habitat improvement project. In contrast, Brown Trout were consistently observed utilizing restored habitats within the mainstem that were originally designed and constructed to improve Brook Trout habitat suitability.

Movement is a critical component of a fish's life history (Fausch et al. 2002). Quantifying the movement of individual organisms is a practical method for assessing their habitat selection and response to restoration activities. Since trout have been documented to be highly mobile, habitat selective animals (Gowan \& Fausch 1996, Petty \& Grossman 2004), they are suitable study subject for the response of coldwater species to physical habitat improvements. The results of this study provide interesting observations on fish movement in response to environmental conditions and habitat restoration efforts.

The study area of Shavers Fork provided a rare opportunity to observe the behavioral response of fish to habitat restoration efforts. The previous research of Hansbarger et al. (2008) provided a baseline of movement patterns in pre-restoration Shavers Fork against which postrestoration data could be compared. It is evident from this body of information that Brook Trout can engage in extensive movement and dispersal behavior throughout the mainstem channel and into tributary systems, but generally exhibit little intra-tributary movement 
This study lends support to the growing body of research (Hutchings et al. 2002, Bridcut et al. 1993, Radinger et al. 2013) asserting the hypothesis of distinct mobile and stationary groups of individuals within populations of salmonids. Some Brook Trout tagged in this study remained in the mainstem channel and closely associated with thermal refugia in both the 2015 and 2016 field seasons. Also, while most Brown Trout exhibited extremely limited movement throughout both seasons, two of the nine Brown Trout tagged in this study exhibited movement of greater than $1 \mathrm{~km}$ - in one case the same fish was tagged in both field seasons and engaged in notably similar movement patterns both years- to the extent of association with the same distinct structure pool habitat in both field seasons.

The observed habitat selectivity in Brook Trout has profound implications for management and restoration planning, as native fish communities may be more responsive on a population scale to efforts that focus on facilitating access to suitable habitat than they would be to physical improvement of in-channel habitat in streams and rivers. The observation of tagged fish in reconnected tributary systems indicates that these restorative efforts are at least practicable in facilitating access to previously severed tributary habitat. Additionally, fish moving into headwater systems which had been treated with limestone sand to reduce $\mathrm{pH}$ barriers are a secondary example of fish interacting on at least some level with restorative efforts, though these relationships are more difficult to quantify than those of systems with restored tributary access, due to the downstream-diffusive nature of water treatment.

Overall, Brook Trout exhibited much higher mean total movement (3.09 km) than Brown Trout $(1.07 \mathrm{~km})$ throughout the course of both the 2015 and 2016 field seasons. Brook Trout were observed in second-order tributaries and intermittent floodplain tributaries close to the main-stem as well as lower order perennial streams and headwaters. Brook Trout were also observed in a few cases in the mainstem channel, always in close proximity to a tributary confluence or lateral cold water source. Upon reaching specific headwater habitats, Brook 
Trout exhibited very little intra-tributary movement, and in many cases occupied a single HCU throughout the length of a field season. This behavior suggests an environmentally-cued movement by Brook Trout into specific habitats in tributary systems. The variety of habitat selection among individuals and widespread dispersal of fish indicate the importance of considering large-scale fluvial systems in the management of Appalachian Brook Trout, with connectivity and access to suitable habitat being pivotal factors.

The data collected in this study were consistent with the first major observation of telemetry surveys conducted in the upper Shaver's Fork watershed (Petty et al. 2012), which demonstrated significant variation in movement patterns between Brook Trout on the mainstem versus fish in tributaries. This difference in movement was likely driven by the availability of thermal refugia in tributary systems compared to relatively little suitable thermal refuge on the mainstem channel, which decreased with rising stream temperatures (Goniea et al. 2006, Petty et al. 2012). There was, however a significant difference ( $D=0.35, p=0.02)$ between dispersal of comparably sized fish of both the 2015 and 2016 field seasons versus the pre-restoration study. However, statistical tests on dispersal of Brook Trout of individual tagging seasons compared to the pre-restoration survey group provide variable results. There is a statistically significant difference in dispersal rate in Brook Trout from the 2015 field season $(D=0.458, p=$ $0.05)$ versus fish from the pre-restoration study. On the other hand, there was no statistically significant difference in dispersal rate of Brook Trout tagged in the 2016 field season from the pre-restoration tagging group $(D=0.406, p=0.095)$.

The results of this study differ in some ways from those of the pre-restoration study on Shaver's Fork, which found a net upstream directional tendency in the movement of Brook Trout tagged in the summer months. Lower precipitation and reduced flows throughout the summer season have been established to contribute to changes in habitat selectivity and movement in salmonids around the world (Aadland 1993, Koehn et al. 2014, Papadaki et al. 2016). Changing 
climatological conditions could potentially lead to shifts in rainfall and altered flow regimes in high elevation stream systems (Safeeq et al. 2014, Vano \& Lettenmaier 2014). This change could have an additional impact on habitat selectivity and movement patterns of Brook Trout in high-elevation stream habitats.

However, in common with the pre-restoration study, this survey found that Brook Trout inhabiting the mainstem of Shavers Fork exhibited significant total movement rates (mean = 30.6 meters/day). However, there was no established directional up or down stream tendency to this movement- and these fish exhibited significantly $(p<0.001)$ lower movement rates than those which moved into tributaries (mean $=61.75$ meters/day). This indicates that postrestoration, Brook Trout on Shaver's Fork continue to exhibit highly mobile behaviors throughout the early summer, but they may now be more downstream-mobile than observed in the prerestoration study.

The previous movement study on Shaver's Fork asserted that including a larger spatial area to account for different and smaller tributary systems would provide a more representative dataset of fish movement throughout the system. It does appear that including all tributaries of the extreme headwaters of Shaver's Fork provides a more complete representation of movement in the system. Many different larger second order streams and intermittent tributaries held fish throughout both the 2015 and 2016 field season, lending support to the 'watershed-scale' nature of this study and analysis.

Discharge data is only available for the 2001 season of the pre-restoration study, and indicates a generally drier year with lower flows than either 2015 or 2016 . The 2015 field season appears to have been a consistently wet, higher-flow season, while over the summer of 2016 discharge was relatively low (however, with one punctuated, extremely high-flow flood event (Figures 6 and 7). 
It is important to note the difference in tagging group between this study and the prerestoration study of fish movement on Shaver's Fork. In that study, the smallest taggable fish were 72 grams and approximately $175 \mathrm{~mm}$. This size difference could lead to variation in observed movement in tagged fish. The pre-restoration survey of Shaver's Fork asserted that expanding the size group to include smaller groups of fish could provide a more complete picture of fish movement on Shaver's Fork. The results of comparisons between smaller fish tagged in this study versus the larger fish tagged in the pre-restoration study do not point towards a significant difference in dispersal or movement between large (72-205g) and small (50-72g) fish either within or between the two surveys. However, the direct comparison of similar (large) size classes of fish does indicate a significant response in fish dispersal post versus pre-restoration on Shaver's Fork.

An additional causal mechanism which could explain the differences in movement and dispersal metrics could be the disparity between relatively sedentary individual Brook Trout and highly mobile ones (Marin 2010). This difference in movement patterns among individuals within a species has been observed in many different groups of fish (Olsson et al. 2006, Stolarski \& Hartman, 2010, Petty \& Grossman 2004). The differences in movement among groups of fish tagged in this study could also be explained by the competitive interactions between Brook and Brown Trout.

There were also consistent and pronounced differences in movement rates of Brook and Brown Trout tagged in this study. Previous studies have recorded strongly restricted diel and seasonal movement of Brown Trout in river systems across the United States (Bunnell et al. 1998, Young 1999). The widespread and rapid dispersal of most Brook Trout from the mainstem into tributary systems, and the specific association of Brown Trout with habitat structures and thermal refugia on the mainstem in both survey seasons contribute to the 
recognition of strong habitat selectivity by trout species. This quality was verified by the habitat data (HCU) collected as a part of this study.

Interestingly, Brook Trout were never found to associate with restored mainstem habitats, which were specifically designed to provide thermal refugia and improve overall habitat suitability. This was established by observations in both field seasons and Chi-squared analysis of association to restored habitat sections for the 2015 and 2016 field seasons. This lack of association could potentially be due to the previously-stated (Fausch et al. 1981, Hitt et al. 2016, Dewald et al. 1992) negative interactions between native Brook Trout and exotic Brown Trout, or because mainstem pool habitats may not have provided the intended thermal refuge for Brook Trout on the mainstem channel. If mainstem pool habitats did not provide the necessary thermal refuge for Brook Trout, that is one potential causal mechanism for their dispersal from the mainstem and into tributary systems. More analysis of temperature data from constructed pool habitats is necessary to fully understand the interaction between Brook and Brown Trout on the mainstem channel of Shavers Fork.

Fausch et al. (1981) found that the removal of Brown Trout from a stream system led to Brook Trout occupying more preferential resting habitat, pointing towards a previous competitive exclusion of Brook Trout from preferential habitat by Brown Trout. Brook Trout could also be averse to remaining in such habitats due to the presence of a potential predator in a large Brown Trout. Additional studies (Hitt et al. 2016, Dewald et al. 1992) have indicated that Brown Trout influence the use of foraging habitat and thermal refugia by Brook Trout in experimental stream settings, leading to decreased growth rates and associated behavioral responses in the Brook Trout. Therefore, the differences in movement between Brook and Brown Trout on Shavers Fork could be due to Brown Trout occupying preferential mainstem feeding habitats.

The results of this study indicate that Brook Trout either had little to no interaction with structure pools on the mainstem channel, or those that did interact with the structure pools were 
removed from the study area. It is possible that these structure pools were used as 'holdover' habitats by Brook Trout on their movement throughout the mainstem and into tributary systemsand this behavior went unrecorded by locational tracks. However, it is evident that there was no verifiable long-term association by Brook Trout with these habitat features (Figures 13 \& 14).

Another potential influencing factor on the observed movement and habitat structure use of Brook and Brown Trout on shaver's Fork is angling. The upper reaches of Shaver's Fork are specially managed by the WVDNR as a stocked trout stream, with Rainbow Trout stocked by railcar at several points throughout the mainstem. Shaver's Fork is frequently fished throughout the Spring and early Summer, with anglers travelling from throughout West Virginia and other states. In personal communication with several anglers throughout the 2015 and 2016 field seasons, it was learned that the habitat structure pools on Shaver's Fork are frequently targeted by anglers and heavily fished.

The observation of this study that no Brook Trout were found associating with structure pools could therefore potentially be due to the fact that those fish which remained in these constructed habitats were targeted by anglers, caught, and removed from the system. This process could lead to restored mainstem habitats becoming attractive population sinks through fish which moving into these otherwise suitable habitats are removed from the system by human activity. Due to the higher proportions of Brook Trout tagged in this study at each surgery site, an angler fishing a structure pool habitat nearest to a given surgery site would have a much higher likelihood of encountering a tagged Brook Trout than a tagged Brown Trout.

For instance, in the 2015 field season, 4 of the 8 fish that were not resolved with locational tracks after tagging were all tagged in proximity to a single constructed pool habitat. If this pool acted as its intended mainstem refuge habitat, it is possible it attracted these Brook Trout only to later be directly focused by angling pressure. Angling regulations and fishing pressure can influence size class and abundance of trout (Brana, 1992, Young \& Hayes 2004, 
Harkonen et al. 2014). Angling could therefore potentially skew results away from more sedentary Brook Trout on the mainstem as they are caught and removed from the system, leading to a bias towards the highly-mobile individuals which moved into tributary systems.

Further research needs to be completed in order to quantify the effects of both competition of Brown Trout with native Brook Trout and angling pressure on restored habitat systems. These two factors remain as vastly understudied and potentially extremely important limiting factors on native trout in Appalachian streams. Only once competitive interactions and angling pressure are better understood will we be capable of effectively managing Brook Trout in this and other high-elevation stream systems. The Shavers Fork Mainstem has been shown to be an extremely important dispersal corridor and supplementary foraging habitat for Brook Trout (Petty et al. 2012). Fish which remained in the mainstem likely did so to exploit higher resource availability and primary productivity located there. However, the majority of fish were observed to move into tributaries very quickly (within 10 days), supporting the importance of the mainstem channel as a movement corridor.

An unexpected observation of this field study was the use of intermittent floodplain tributaries and side channels off the mainstem in the summer of both 2015 and 2016 by Brook Trout (Figure 22). In the majority of cases, Brook Trout moved into second-order tributary systems and many individuals swam to the extreme headwaters reaches of these streams. The major tributary of Second Fork (which was treated with limestone sand in an effort to reduce acidity) held the highest number of fish of any tributary in both the 2015 and 2016 field season. However, a small number of Brook Trout in both field seasons made use of intermittent systems and temporary streams throughout the summer. Because these areas are not widely considered as essential fish habitat and in many cases, are not protected by regulation or enforcement, they are worthy of additional study and consideration by those tasked with management of Brook Trout populations throughout their native range. 
The limitations of this study include potential bias towards highly mobile Brook Trout due to less mobile fish being targeted and caught by anglers, and issues with dispersal metrics due to net downstream movement from tagging site followed by extensive up-tributary movement, as well as potential issues with comparisons to the pre-restoration study due to natural seasonal variation of environmental parameters within the watershed. Extensive effort was undertaken to ensure that no fish were 'lost' from the survey due to natural movement patterns throughout the watershed- the mainstem and all located tributaries for $5 \mathrm{~km}$ downstream from the 'Beaver Creek' surgery site were included in tracking surveys. The broad spatial gain of this study has led to a documentation of widespread Brook Trout movement and response to restoration activities on a watershed scale. 


\section{CONCLUSIONS \& MANAGEMENT IMPLICATIONS}

The management implications of such wide-ranging and variable movement behaviors in native fish are manifold. Due to the dispersive mobility observed in Brook Trout in this study, it was not possible to establish a relationship between Brook Trout and constructed pool habitats on the mainstem channel. There was, however, evidence of fish utilizing improved fish access culverts in the systems of Beaver Creek and Lamothe Hollow in the 2016 field season. The dramatic movement of Brook Trout into tributaries, as well as movement into previously isolated systems suggests that reconnecting tributaries will likely be the most beneficial to Brook Trout metapopulations at the riverscape scale.

Brook Trout on Shavers Fork may have benefited more from improved access to historically severed tributary systems and headwater treatment for acidity than from the physical construction of pool habitats on the mainstem channel. It is worth restating that angling pressure on structure pools may have had a negative impact on resolving tracks of Brook Trout in the mainstem of Shaver's Fork due to fishing effort being reportedly focused on the constructed pools. However, that conclusion would only be supported by the observations of this study if angling pressure was disproportionately selective on Brook Trout. Additionally, Brook Trout could have utilized structure pools as 'holding habitat' in their movements up and down the mainstem towards major tributary systems. While the data collected in this study show no association between Brook Trout and constructed mainstem stream habitats, it does provide a verifiable relationship between native fish communities and improved access to headwater tributaries through both physical and chemical barrier removal.

The dispersal of Brook Trout throughout the headwaters of Shavers Fork into tributary systems lends to the growing body of evidence that native fisheries management must be directed on the appropriate spatial scale or grain to effect positive change. Incorporating watershed-scale studies into management practicum could lead to a better understanding of the 
relationship between aquatic organisms and restoration activities- an understanding which is difficult to achieve when considering ecological metrics on a stream segment or channel unit scale. It additionally adds support to the case for selectivity when choosing between restoration methodologies being applied in high-elevation stream systems, as aquatic communities may benefit significantly more from improved access to historically available suitable habitat rather than physical construction of such habitat in mainstem channels.

The results of this study indicate that restoration efforts directed at strengthening the metapopulation structures of Brook Trout throughout their historic range may be most effective when they focus upon restoring the natural connectivity of habitat, rather than attempting to use structures to improve thermal refugia on mainstem systems. By continuing to observe the movements of fish in post-restoration Shaver's Fork and cataloging their response to seasonal and environmental variables, we can continue to add to our understanding of spatial fish ecology and the efficacy of restoration efforts directed at native fish species throughout coldwater habitats in the southern Appalachians. 


\section{LITERATURE CITED}

Aadland, L. (1993) Stream Habitat Types: Their Fish Assemblages and Relationship to Flow. Transactions of the American Fisheries Society. 13 (4) pp. 790-806.

Adams, N., Rondorf, D. Evans, S. (1998) Effects of surgically and gastrically implanted radio transmitters on swimming performance and predator avoidance of juvenile chinook salmon (Onchorhynchus tshawytscha). Canadian Journal of Fisheries and Aquatic Science. 55 (4) pp. 781-787.

Bachman, R. (1984) Foraging Behavior of Free-Ranging Wild and Hatchery Brown Trout in a Stream. Transactions of the American Fisheries Society. 113 (1) pp. 1-32.

Beechie, T., Pess, G., Imaki, H., Martin, A., Alvarez, J., Goodman, D. (2014) Comparison of potential increases in juvenile salmonid rearing habitat capacity among alternative restoration scenarios, Trinity River, California. Restoration Ecology. 23(1) pp.75-84.

Bennett, D. (2012) WV Gazette Article: "\$5 Million project aims to restore Brook Trout"- personal quotation, article by J. McCoy, published 10/25/2012, Available from:

[www.wvgazettemail.com/News/201210250196]

Bridcut, E. and Giller, P. (1993) Movement and site fidelity in young brown trout Salmo trutta populations in a southern Irish stream. Journal of Fish Biology. 43 (6) pp. 889-899.

Brown, R., Mackay, W. (1995) Fall and Winter Movements of and Habitat Use by Cutthroat Trout in the Ram River, Alberta. Transactions of the American Fisheries Society. 124 (6) pp.873-885.

Buisson, L., Thuiller, W., Lek, S. (2008) Climate change hastens the turnover of stream fish assemblages. Global Change Biology. 14 (10) pp. 2232-2248.

Bunnell, D., Isely, J., Burrell, K., Van Lear, D. (2011) Diel Movement of Brown Trout in a Southern Appalachian River. Transactions of the American Fisheries Society. 127 (4) pp. 630636.

Cargill, A. (2011) Lack of Rainbow Trout Movement in a Small Stream. Transactions of the American Fisheries Society. 109 (5) pp. 484-490.

Clapp, D., Clark, R., Diana, J. (1990) Range, Activity, and Habitat of Large, Free-Ranging Brown Trout in a Michigan Stream. Transactions of the American Fisheries Society. 119 (6) pp.1022-1034.

Clements, S., Jepsen, D., Karnowski, M., Schreck, C. (2005) Optimization of an Acoustic Telemetry Array for Detecting Transmitter-Implanted Fish. North American Journal of Fisheries Management. 25 (2) pp.429-436.

Cooke, S., Murchie., K., Schreer, J. (2004) Effects of radio-transmitter antenna length on swimming performance of juvenile rainbow trout. Ecology of Freshwater Fish. 13 (4) pp.312316. 
Cooke, S., Woodley, C., Eppard, M., Brown, R. (2011) Advancing the surgical implantation of electronic tags in fish: a gap analysis and research agenda based on a review of trends in intracoelomic tagging effect studies. Reviews in Fish Biology \& Fisheries. 21 (1) pp. 127-151.

Curry, R., Sparks, D., van de Sande, J. (2002) Spatial and Temporal Movements of Riverine Brook Trout Populations. Transactions of the American Fisheries Society. 131 (3) pp.551-560.

Courtois, L. (1981) Lightweight, Adjustable, and Portable Surgical Table for Fisheries Work in the Field. The Progressive Fish Culturist. 43 (1) pp.55-56.

De Jong, M., Cowx, I., Scruton, D. (1997) An Evaluation of Instream Habitat Restoration Techniques on Salmonid Populations in a Newfoundland Stream. Regulated Rivers: Research and Management. 13 pp.603-614.

Dewald, L. and Wilzbach, M. (1992) Interactions between Native Brook Trout and Hatchery Brown Trout: Effects on Habitat Use, Feeding and Growth. Transactions of the American Fisheries Society. 121 (3) pp. 287-296.

Eaglin, G., and Hubert, W. (1993) Management Briefs: Effects of Logging and Roads on Substrate and Trout in Streams of the Medicine Bow National Forest, Wyoming. North American Journal of Fisheries Management. 13 (4) pp.844-846

Eaton, J., and Scheller, R. (1996) Effects of climate warming on fish thermal habitat in streams of the United States. Limnology and Oceanography. 41 (5) pp. 1109-1115.

Fausch, K., White, R. (1981) Competition Between Brook Trout (Salvelinus fontinalis) and Brown Trout (Salmo trutta) for Positions in a Michigan Stream. Canadian Journal of Fisheries and Aquatic Sciences. 38 (10) pp.1220-1227.

Fausch, K., Torgersen, C., Baxter, C., Li, H. (2002) Landscapes to Riverscapes: Bridging the Gap between Research and Conservation of Stream Fishes. Bioscience. 52 (6) pp.483-498.

Freund, J. and Hartman, K. (2002) Influence of Depth on Detection Distance of Low-Frequency Radio Transmitters in the Ohio River. North American Journal of Fisheries Management. 22 (4) pp.1301-1305.

Gerking, S. (1953) Evidence for the Concepts of Home Range and Territory in Stream Fishes. Ecology. 34 (2) pp.347-365.

Gerking, S. (1959) The restricted movement of fish populations. Biological Review of the Cambridge Philosophical Society. 34 (2) pp.221-242.

Goniea, T., Keefer, M., Bjornn, T., Peery, C., Bennett, D., Stuehrenberg, L. (2006) Behavioral Thermoregulation and Slowed Migration by Adult Fall Chinook Salmon in Response to High Columbia River Water Temperatures. Transactions of the American Fisheries Society. 135 (2) pp.408-419.

Gowan, C., Fausch, K., Young, M. (1994) Restricted Movement in Resident Stream Salmonids: A Paradigm Lost? Canadian Journal of Fisheries and Aquatic Sciences. 51 (11) pp.2626-2637. 
Gowan, C. and Fausch, K. (1996) Mobile Brook Trout in two high-elevation Colorado streams: reevaluating the concept of restricted movement. Canadian Journal of Fisheries and Aquatic Sciences. 53 (6) pp. 1370-1381.

Habera, J. and Moore, S. (2005) Managing Southern Appalachian Brook Trout. Fisheries. 30 (7) pp. 10-20.

Hansbarger, J., Petty, J., \& Mazik, P. (2008) Brook Trout movement within a high-elevation watershed: consequences for watershed restoration. Proceedings from the Conference on the Ecology and Management of High-Elevation Forests in the Central and Southern Appalachian Mountains. pp.74-84.

Harden, C. (2006) Human impacts on headwater fluvial systems in the northern and central Andes. Geomorphology. 79 (4) pp.249-263.

Harkonen, L., Hyvarinen, P., Paappanen, J., Vanikka, A. (2014) Explorative behavior increases vulnerability to angling in hatchery-reared Brown Trout (Salmo trutta). Canadian Journal of Fisheries and Aquatic Sciences. 71 (12) pp. 1900-1909.

Hart, L. and Summerfelt, R. (1975) Surgical Procedures for Implanting Ultrasonic Transmitters into Flathead Catfish (Pylodictis olivaris). Transactions of the American Fisheries Society. 104 (1) pp.56-59.

Hartman, K.J. and J.P. Hakala. (2006) Relationships between fine sediment and brook trout recruitment in forested headwater streams. Journal of Freshwater Ecology. 21 pp.215-230.

Hartman, K.J. and M.N. Logan. (2010) Movement and habitat use by transplanted adult brook trout in an Appalachian headwater stream. Northeastern Naturalist. 17 (3) pp.357-372.

Hartman, G., and Brown, T. (2011) Use of Small, Temporary, Floodplain Tributaries by Juvenile Salmonids in a West Coast Rain-Forest Drainage Basin, Carnation Creek, British Columbia. Canadian Journal of Fisheries and Aquatic Sciences. 44 (2) pp.262-270.

Harvey, B. (1998) Influence of large woody debris on retention, immigration, and growth of costal cutthroat trout (Oncorhynchus clarki clarki) in stream pools. Canadian Journal of Fisheries and Aquatic Sciences. 55 (8) pp.1902-1908

Harvey, B., Nakamoto, R., White, J. (1999) Influence of large woody debris and a bankfull flood on movement of adult resident coastal cutthroat trout (Oncorhynchus clarki) during fall and winter. Canadian Journal of Fisheries and Aquatic Sciences. 56 (11) pp.2161-2166.

HItt, N., Snook, E., Massie, D. (2016) Brook trout use of thermal refugia and foraging habitat influenced by Brown Trout. Canadian Journal of Fisheries and Aquatic Sciences. 74 (3) pp. 406418.

Hildebrand, R.H., Cemly A.D., Dolloff, C., Harpster, K (1997) Effects of woody debris placement on stream channel and benthic macroinvertebrates. Canadian Journal of Fisheries and Aquatic Sciences. 54 pp.931-939. 
Hudy, M., Thieling, T., Gillespie, N., Smith, E. (2008) Distribution, Status, and Land Use Characteristics of Subwatersheds within the Native Range of Brook Trout in the Eastern United States. North American Journal of Fisheries Management. 28 pp. 1069-1085.

Hughes, R., Kaufmann, P., Herlihy, A., Kincaid, T., Reynolds, L., Larsen, D. (1998) A process for developing and evaluating indices of fish assemblage integrity. Canadian Journal of Fisheries and Aquatic Sciences. 55 (7) pp.1618-1631.

Hughes, N. (1999) Population processes responsible for larger-fish-upstream distribution patterns of Arctic Grayling (Thymallus arcticus) in interior Alaskan runoff rivers. Canadian Journal of Fisheries and Aquatic Sciences. 56 (12) pp.2292-2299.

Hutchings, J. and Gerber, L. (2002) Sex-based dispersal in a salmonid fish. Proceedings of the Royal Society of Biological Sciences. 269 (1508)

Isaak, D., Wenger, S., Luce, C. (2011) Flow regime, temperature, and biotic interactions drive differential declines of trout species under climate change. Proceedings of the National Academy of Sciences of the USA. 108 (34) pp. 14175-14180.

Jepsen, N., Koed, A., Thorstad, E., Baras, E. (2002) Surgical implantation of telemetry transmitters in fish: how much have we learned? Hydrobiologia. 165 pp.239-248.

Kaeding, L. (1996) Summer Use of Coolwater Tributaries of a Geothermally Heated Stream by Rainbow and Brown Trout, Onchorhynchus mykiss and Salmo trutta. The American Midland Naturalist. 135 (2) pp.283-292.

Kaushal, S., Likens, G., Jaworski, N. (2010) Rising stream and river temperatures in the United States. Frontiers in Ecology and the Environment. 8 (9) pp.461-466.

Koehn, J., King, A., Beesley, L., Copeland, C., Zampatti, B., Mallen-Cooper, M. (2014) Flows for native fish in the Murray-Darling Basin: lessons and considerations for future management. Ecological Management \& Restoration. 15 (1) pp.40-50.

Koljonen, S., Huusko, A., Maki-Petays, A., Louhi, P., Muotka, T. (2013) Assessing Habitat Suitability for Juvenile Atlantic Salmond to In-Stream Restoration and Discharge Variability. Restoration Ecology. 21 (3) pp.344-352.

Kratzer, J. and Warren, D. (2013) Factors Limiting Brook Trout Biomass in Northeastern Vermont Streams. North American Journal of Fisheries Management. 33 (1) pp.130-139.

Larson, G. and Moore, S. (1985) Encroachment of Exotic Rainbow Trout into Stream Populations of Native Brook Trout in the Southern Appalachian Mountains. Transactions of the American Fisheries Society. 114 (2) pp.195-203.

Lasalle, G. and Rochard, E. (2008) Impact of twenty-first century climate change on diadromous fish spread over Europe, North Africa and the Middle East. Global Change Biology. 15 (5) pp.1072-1089.

Li, H., Lamberti, G., Pearsons, T., Tait, C., Li, J., Buckhouse, J. (2011) Cumulative Effects of Riparian Disturbances Along High Desert Trout Streams of the John Day Basin, Oregon.

Transactions of the American Fisheries Society. 123 (4) pp.627-640. 
Lima, S. and Zollner, P. (1996) Towards a behavioral ecology of ecological landscapes. Trends in Ecology \& Evolution. 11 (3) pp.131-135.

Marschall, E. and Crowder, L., (1996) Assessing Population Responses to Multiple Anthropogenic Effects: A Case Study with Brook Trout. Ecological Applications. 6 (1) pp.152167.

McDonnell, T., Sloat, M., Sullivan, T., Dolloff, C. (2015) Downstream Warming and Headwater Acidity May Diminish Coldwater Habitat in Southern Appalachian Mountain Streams. PLoS ONE. 10 (8) 0134757.

Meehan, W.R. (1991) Influences of forest and rangeland management on salmonid fishes and their habitats: introduction and overview. Food \& Agriculture Organization AGRIS online database Available from :[http://agris.fao.org/] retrieved June 10, 2016.

Menendez, R., Clayton, J., Dannaway, E., Rauch, H., Renton, J., Sherlock, S., Zurbuch, P. (1998) Application of Limestone to Restore Fish Communities in Acidified Streams. North American Journal of Fisheries Management. 18 (2) pp.347-360.

Metcalfe, J. and Arnold, G. (1997) Tracking fish with electronic tags. Nature. 387 (6634) pp. 665-666.

Meyers, L., Thuemler, T., Kornley, G. (1992) Seasonal Movements of Brown Trout in Northeast Wisconsin. North American Journal of Fisheries Management. 12 (3) pp.433-441.

Minshall, G., Brock, J., Varley, J. (1989) Wildfires and Yellowstone's Stream Ecosystems. Bioscience. 39 (10) pp.707-715.

Mollenhaur R., Wagner, T., Kepler, M., Sweka, J. (2013) Fall and Early Winter Movement and Habitat Use of Wild Brook Trout. Transactions of the American Fisheries Society. 142 (5) pp.1167-1178.

Mucha, J. and Mackereth, R. (2008) Habitat Use and Movement Patterns of Brook Trout in Nipigon Bay, Lake Superior. Transactions of the American Fisheries Society. 137 (4) pp.12031212.

Myers, B., Doloff, A., Rypel, A. (2014) Rainbow trout versus brook trout biomass and production under varied climate regimes in small southern Appalachian streams. Proceedings: looking back and moving forward. Bozeman, MT. Wild Trout XI Symposium: pp: 127-135.

Nakano, S., Kitano, F., Maekawa, K., (1996) Potential fragmentation and loss of thermal habitats for charrs in the Japanese archipelago due to climatic warming. Freshwater Biology. 36 (3) pp.711-722.

Nickelson, T. and Rodgers, J. (1992) Seasonal Changes in Habitat Use by Juvenile Coho Salmon (Oncorhynchus kisutch) in Oregon Coastal Streams. 49 (4) pp.783-789.

Nilsson, C., Reidy, C., Dynesius, M., Revenga, C. (2005) Fragmentation and Flow Regulation of the World's Large River Systems. Science. 308 (5720) pp.405-408. 
Olsson, I., Greenberg, L., Bergman, E., Wysujack, K. (2006) Environmentally induced migration: the importance of food. Ecology Letters. 9 (6) pp. 645-651.

Papadaki, C., Soulis, K., Munoz-Maz, R., Martinez-Capel, F., Zogaris, S., Ntoanidis, L., Dimitriou, E. (2016) Potential impacts of climate change on flow regime and fish habitat in mountain rivers of the south-western Balkans. 540 (1) pp. 418-428.

Petty, J. and Grossman, G. (2004) Restricted movement by mottled sculpin (pisces: cottidae) in a southern Appalachian stream. Freshwater Biology. 49 (5) pp. 631-645.

Petty, J., Lamothe, P., Mazik, P. (2005) Spatial and Seasonal Dynamics of Brook Trout Populations Inhabiting a Central Appalachian Watershed. 134 (3) pp.572-587.

Petty, J. and Thorne, D. (2005) An Ecologically Based Approach to Identifying Restoration Priorities in an Acid-Impacted Watershed. 13 (2) pp.348-357.

Petty, J., Hansbarger, J., Hunstman, B. (2012) Brook Trout Movement in Response to Temperature, Flow, and Thermal Refugia within a Complex Appalachian Riverscape. 141 (4) pp.1060-1073.

Poplar-Jeffers, I., Petty, J., Anderson, J., Kite, S., Strager, M., Fortney, R. (2008) Culvert Replacement and Stream Habitat Restoration: Implications from Brook Trout Management in an Appalachian Watershed, U.S.A. Restoration Ecology. 17 (3) pp.404-413.

Radinger, J. and Wolter, C. (2013) Patterns and predictors of fish dispersal in rivers. Fish and Fisheries 15 (3) pp.456-473.

Rahel, F., Keleher, C., and Anderson, J. (1996) Potential habitat loss and population fragmentation for cold water fish in the North Platte River drainage of the Rocky Mountains; Response to climate warming. Limnology and Oceanography. 41 (5) pp.1116-1123.

Riley, S. and Fausch, K. (1995) Trout populations response to habitat enhancement in six northern Colorado streams. Canadian Journal of Fisheries and Aquatic Sciences. 52 (1) pp.3453.

Rodriguez, M. (2002) Restricted Movement in Stream Fish: The Paradigm is Incomplete, Not Lost. 83 (1) pp.1-13.

Roghair, C. \& Dollofi, C. (2005) Brook Trout Movement during and after Recolonization of a Naturally Defaunated Stream Reach. 25 (3) pp.777-784.

Roni, P., editor. (2005) Monitoring stream and watershed restoration. American Fisheries Society, Bethesda, Maryland.

Roper, B. and Scarnecchia, D. (1994) Summer Distribution of and Habitat Use by Chinook Salmon and Steelhead within a Major Basin of the South Umpqua River, Oregon. 123 (3) pp.298-303.

Ross, M. and Kleiner, C. (1982) Shielded-needle Technique for Surgically Implanting Radiofrequency Transmitters in Fish. 44 (1) pp.41-43. 
Rousell, J., Vilizzi, L., Copp, G. (2004) Assessing variation in suitability curves and electivity profiles in temporal studies of fish and habitat use. River Research and Applications. 2 (3) pp.605-618.

Safeeq, M., Grant, G., Lewis, S., Kramer, M., Staab, B. (2014) A hydrogeologic framework for characterizing summer streamflow sensitivity to climate warming in the Pacific Northwest, USA. Available from: Oregon State University Open Access Articles:

[https://ir.library.oregonstate.edu/xmlui/handle/1957/53827]

Schlosser, I. (1995) Critical landscape attributes that influence fish population dynamics in headwater streams. Hydrobiologia. 303: pp.71-81.

Shepard, B., Al-Chokhachy, R., Koel, T., Kulp, M., Hitt, N. (2016) Likely Responses of Native and Invasive Salmonid Fishes to Climate Change in the Rocky Mountains and Appalachian Mountains. Climate Change in Wildlands, Island Press. pp. 234-255.

Shetter, D. (1968) Observations on Movements of Wild Trout in Two Michigan Stream Drainages. Transactions of the American Fisheries Society. 97 (4) pp. 472-480.

Stolarski, J. and Hartman, K. (2010) Comparisons of growth and condition of fluvial and resident brook trout populations within partially migratory populations. Fisheries Management and Ecology. 17 (1) pp. 33-39.

Swanberg, T. (2011) Movements of and Habitat Use by Fluvial Bull Trout in the Blackfoot River, Montana. Transactions of the American Fisheries Society. 126 (5) pp.735-746.

Sweka \& Hartman (2001) Influence of Turbidity on Brook Trout Reactive Distance and Foraging Success. Transactions of the American Fisheries Society. 130 pp.138-146.

Vano, J. and Lettenmaier, D. (2014) A sensitivity-based approach to evaluating future changes in Colorado River discharge. Climatic Change. 122 (4) pp. 621-634.

Wagner, T., Deweber, J., Detar, J. (2013) Landscape-Scale Evaluation of Asymmetric Interaction between Brown Trout and Brook Trout Using Two-Species Occupancy Models. Transactions of the American Fisheries Society. 142 (2) pp.353-361.

Weltman, M. and Taylor J. (2013) Hydraulic Fracturing and Brook Trout Habitat in the Marcellus Shale Region: Potential Impacts and Research Needs. Fisheries. 38 (1) pp.4-15.

Wigington, P., Ebersole, J., Colvin, M. (2006) Coho salmon dependence on intermittent streams. Frontiers in Ecology and the Environment 4 (10) pp. 513-518.

Winter, J.D. (1983) Underwater Biotelemetry. Fisheries Techniques, American Fisheries Society: pp 371-395.

WVNDR Almanac website, information available from:

[http://www.wvdnr.gov/wildlife/magazine/archive/12Summer/Wild_Almanac.pdf].

Young, M. (1994) Mobility of Brown Trout in south-central Wyoming streams. Canadian Journal of Zoology. 72 (2) pp.2078-2083. 
Young, M. (1996) Summer movements and habitat use by Colorado River cutthroat trout (Oncorhynchus clarki pleuriticus) in small, montane streams. Canadian Journal of Fisheries and Aquatic Sciences. 53 (6) pp. 1403-1408.

Young, M. (1999) Summer diel activity and movement of adult Brown Trout in high-elevation streams in Wyoming, U.S.A. Journal of Fish Biology. 54 (1) pp. 181-189.

Young, R. and Hayes, J. (2004) Angling Pressure and Trout Catchability: Behavioral Observations of Brown Trout in Two New Zealand Backcountry Rivers. North American Journal of Fisheries Management. 24 (4) pp. 1203-1213.

Yu, D., Chen, M., Zhou, Z., Rochard, E., Tang, Q., Liu, H. (2013) Global climate change will severely decrease potential distribution of the East Asian coldwater fish Rhynchocypris oxycephalus (Acinopterygii, Cyprinidae). Hydrobiologia. 700 (1) pp. 23-30 
Figure 1. Map of the upper Shavers Fork watershed

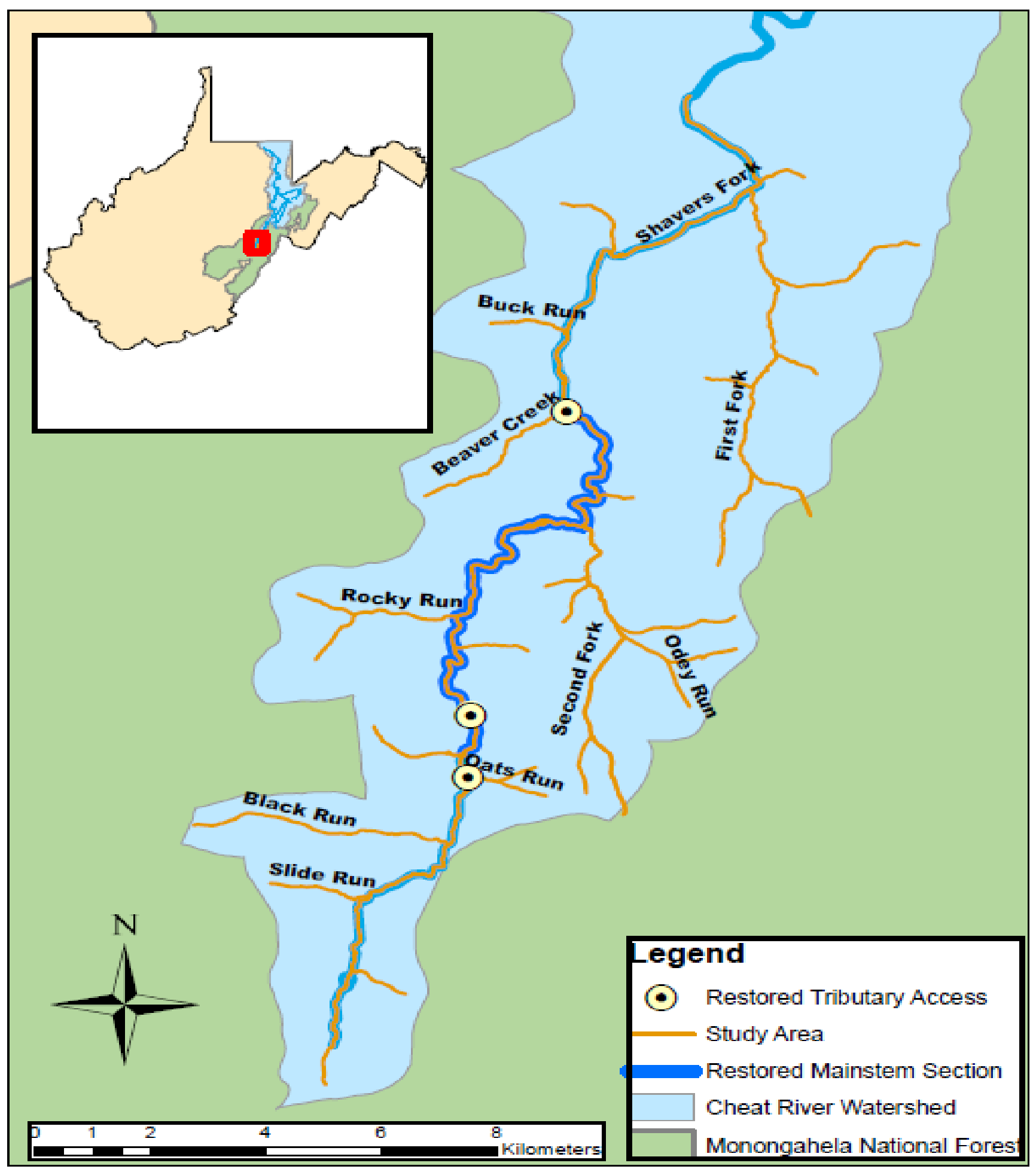


Table 1. Summary of Brook and Brown Trout size, dispersal and movement statistics throughout the 2015 field season. 'Dispersal' indicates net movement up or downstream from the tagging site. Negative values indicate net downstream movement. 'Movement' indicates total stream movement from tagging site.

Brook Trout in Shavers Fork, 2015 Field Season

\begin{tabular}{|l|c|c|c|c|c|c|}
\hline \multicolumn{1}{|c|}{ Variable } & N & Mean & SE & Median & Min & Max \\
\hline Standard Length (mm) & 16 & 177.78 & 4.70 & 175 & 148 & 208 \\
\hline Fish Weight (g) & 16 & 88.07 & 7.18 & 80.8 & 57 & 166.6 \\
\hline Net Dispersal (m) & 16 & -956.25 & 1028.00 & -280 & -8210 & 5370 \\
\hline Net Dispersal rate (m/d) & 16 & -19.25 & 20.81 & -6.47 & -243.03 & 77.82 \\
\hline Total movement (m) & 16 & 3308 & 623.30 & 2905 & 120 & 8210 \\
\hline Total movement rate (m/d) & 16 & 60.86 & 14.52 & 50.51 & 2.5 & 243.03 \\
\hline Days at Large & 16 & 58 & 3.94 & 66 & 25 & 72 \\
\hline
\end{tabular}

Brown Trout in Shavers Fork, 2015 Field Season

\begin{tabular}{|l|c|c|c|c|c|c|}
\hline \multicolumn{1}{|c|}{ Variable } & N & Mean & SE & Median & Min & Max \\
\hline Standard Length (mm) & 4 & 322.2 & 58.3 & 284 & 205 & 450 \\
\hline Fish Weight (g)* & 4 & 330.2 & 47.55 & 317 & 127.7 & $>500$ \\
\hline Net Dispersal (m) & 4 & 1202.5 & 600.23 & 475 & -880 & 2980 \\
\hline Net Dispersal rate (m/d) & 4 & 28.19 & 11.80 & 21.72 & 7.25 & 62.08 \\
\hline Total movement (m) & 4 & 762.5 & 805.28 & 475 & 450 & 2980 \\
\hline Total movement rate (m/d) & 4 & 28.19 & 11.80 & 21.72 & 7.25 & 62.08 \\
\hline Days at Large & 4 & 45 & 9.94 & 44 & 21 & 69 \\
\hline
\end{tabular}

* Brown Trout tagged in this study regularly exceeded the 500 -gram capacity of field scales. Weight for these fish was recorded as " $>500 \mathrm{~g}$ " 
Table 2. Summary of Brook and Brown Trout size, dispersal and movement statistics throughout the 2016 field season. 'Dispersal' indicates net movement up or downstream from the tagging site. Negative values indicate net downstream movement. 'Movement' indicates total stream movement from tagging site.

Brook Trout in Shavers Fork, 2016 Field Season

\begin{tabular}{|l|c|c|c|c|c|c|}
\hline \multicolumn{1}{|c|}{ Variable } & N & Mean & SE & Median & Min & Max \\
\hline Standard Length (mm) & 23 & 174.4 & 4.15 & 174.0 & 145 & 238 \\
\hline Fish Weight (g) & 23 & 84.47 & 7.1 & 77.85 & 44.8 & 205.5 \\
\hline Net Dispersal (m) & 23 & 572.61 & 834.74 & 700 & -9420 & 6550 \\
\hline Net Dispersal rate (m/d) & 23 & 4.56 & 14.44 & 12.83 & -151.94 & 105.65 \\
\hline Total movement (m) & 23 & 2862.17 & 582.52 & 2050 & 10 & 9420 \\
\hline Total movement rate (m/d) & 23 & 50.02 & 9.78 & 33 & 0.833 & 151.94 \\
\hline Days at Large & 23 & 57 & 3.72 & 62 & 12 & 76 \\
\hline
\end{tabular}

Brown Trout in Shavers Fork, 2016 Field Season

\begin{tabular}{|l|c|c|c|c|c|c|}
\hline \multicolumn{1}{|c|}{ Variable } & N & Mean & SE & Median & Min & Max \\
\hline Standard Length (mm) & 5 & 376 & 49.32 & 365 & 215 & 529 \\
\hline Fish Weight (g)* & 5 & 414.88 & 5.38 & $>500$ & 151 & $>500$ \\
\hline Net Dispersal (m) & 5 & 586 & 750.08 & 160 & -1360 & 3180 \\
\hline Net Dispersal rate (m/d) & 5 & 9.08 & 11.49 & 2.32 & -19.71 & 49.69 \\
\hline Total movement (m) & 5 & 1146 & 565.81 & 990 & 40 & 3180 \\
\hline Total movement rate (m/d) & 5 & 17.22 & 8.86 & 13.75 & 0.63 & 49.69 \\
\hline Days at Large & 5 & 68 & 1.57 & 69 & 64 & 72 \\
\hline
\end{tabular}

* Brown Trout tagged in this study regularly exceeded the 500-gram capacity of field scales. Weight for these fish was recorded as " $>500 \mathrm{~g}$ " 
Figure 2. Movement and Dispersal of Brook and Brown Trout in the 2015 tagging group. 'Mean Net Dispersal' indicates net up or downstream movement from tagging site. Negative values indicate net downstream movement.

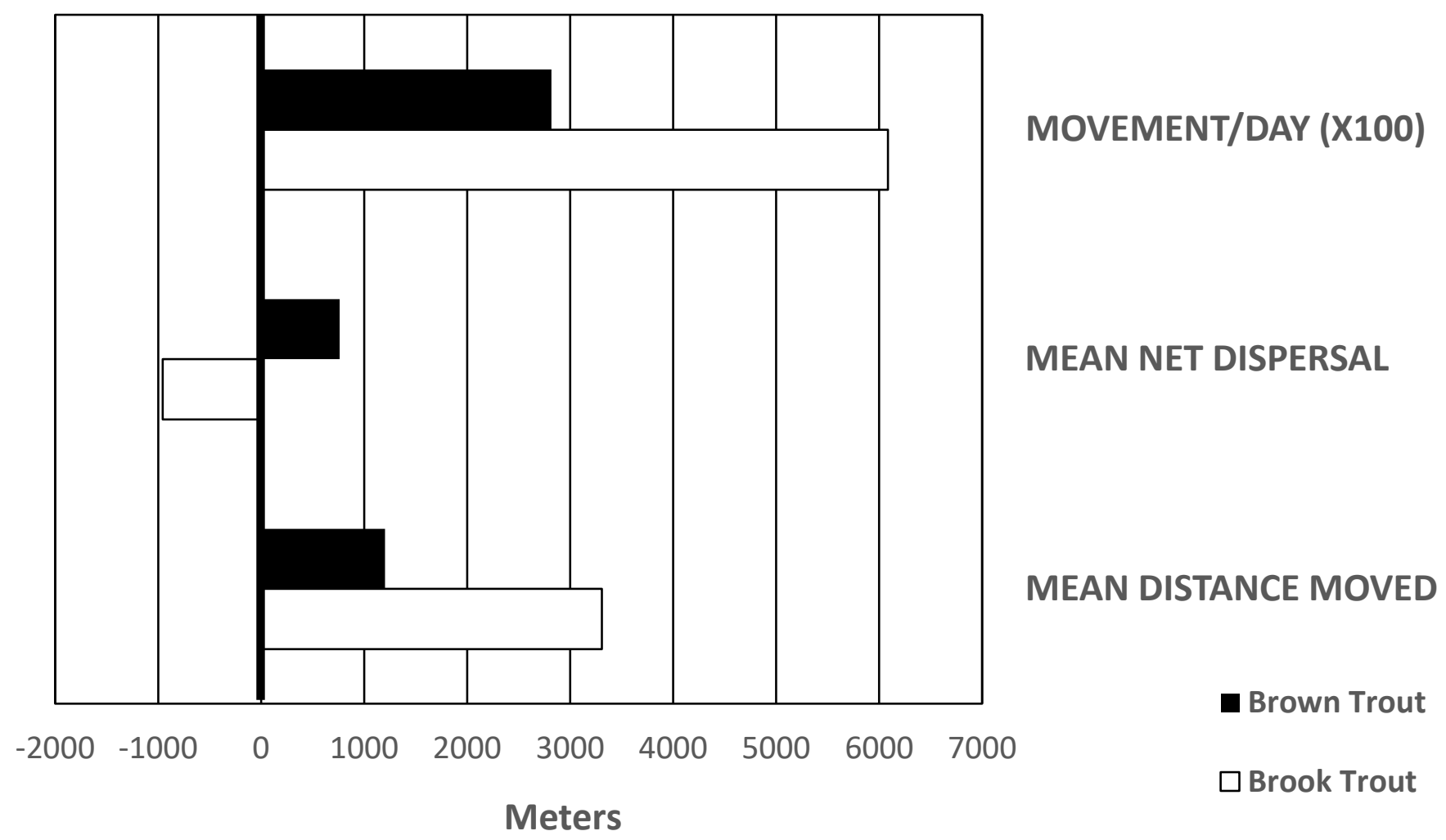


Figure 3. Dispersal Rates for Brook Trout tagged in the 2015 field season. Movement of fish in extreme tails of distribution (e.g. -200) moved downstream from tagging site, and all moved from the mainstem into tributary habitats

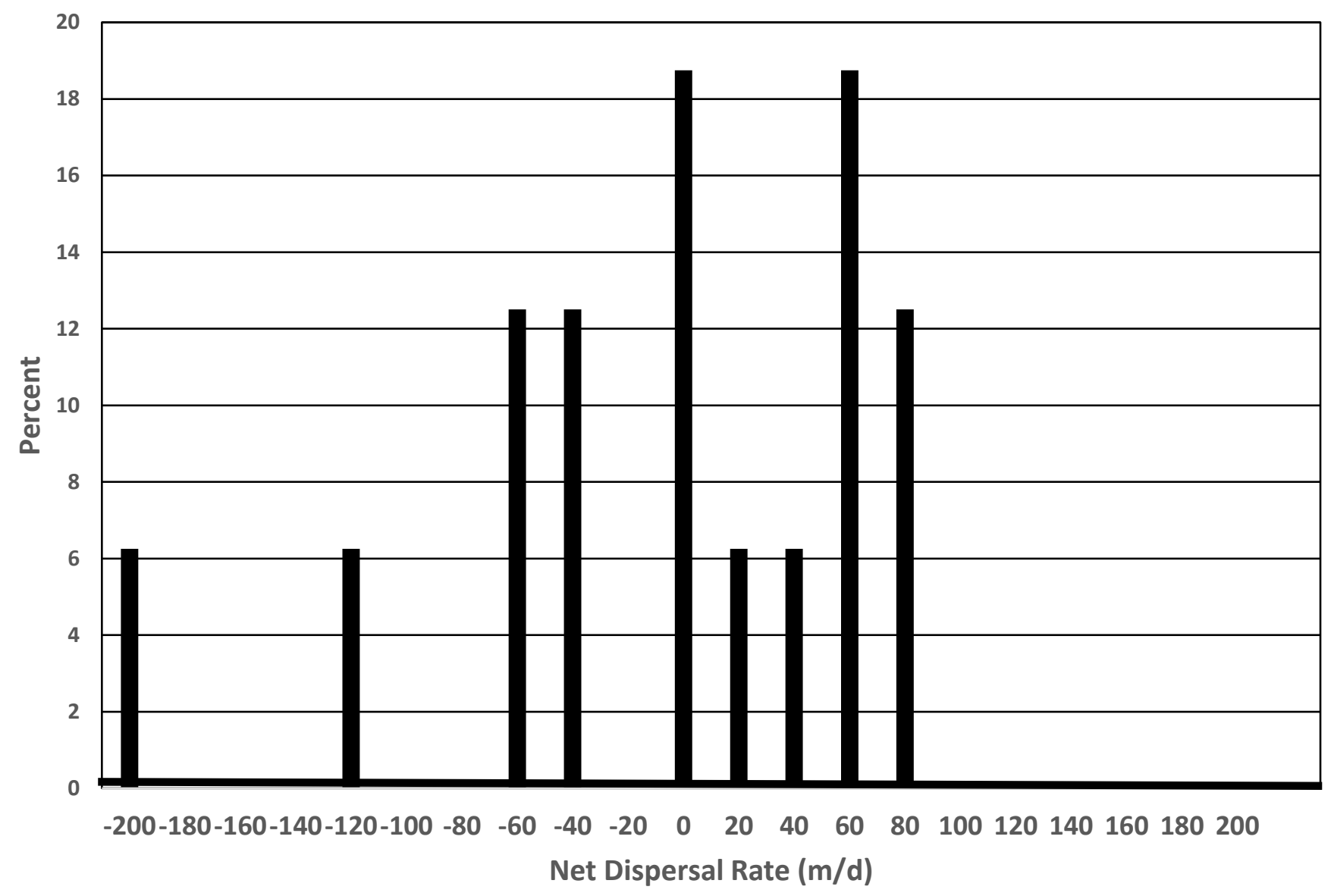


Figure 4. Movement and Dispersal of Brook and Brown Trout in the 2016 tagging group. 'Mean Net Dispersal' indicates net up or downstream movement from tagging site. Negative values indicate net downstream movement.

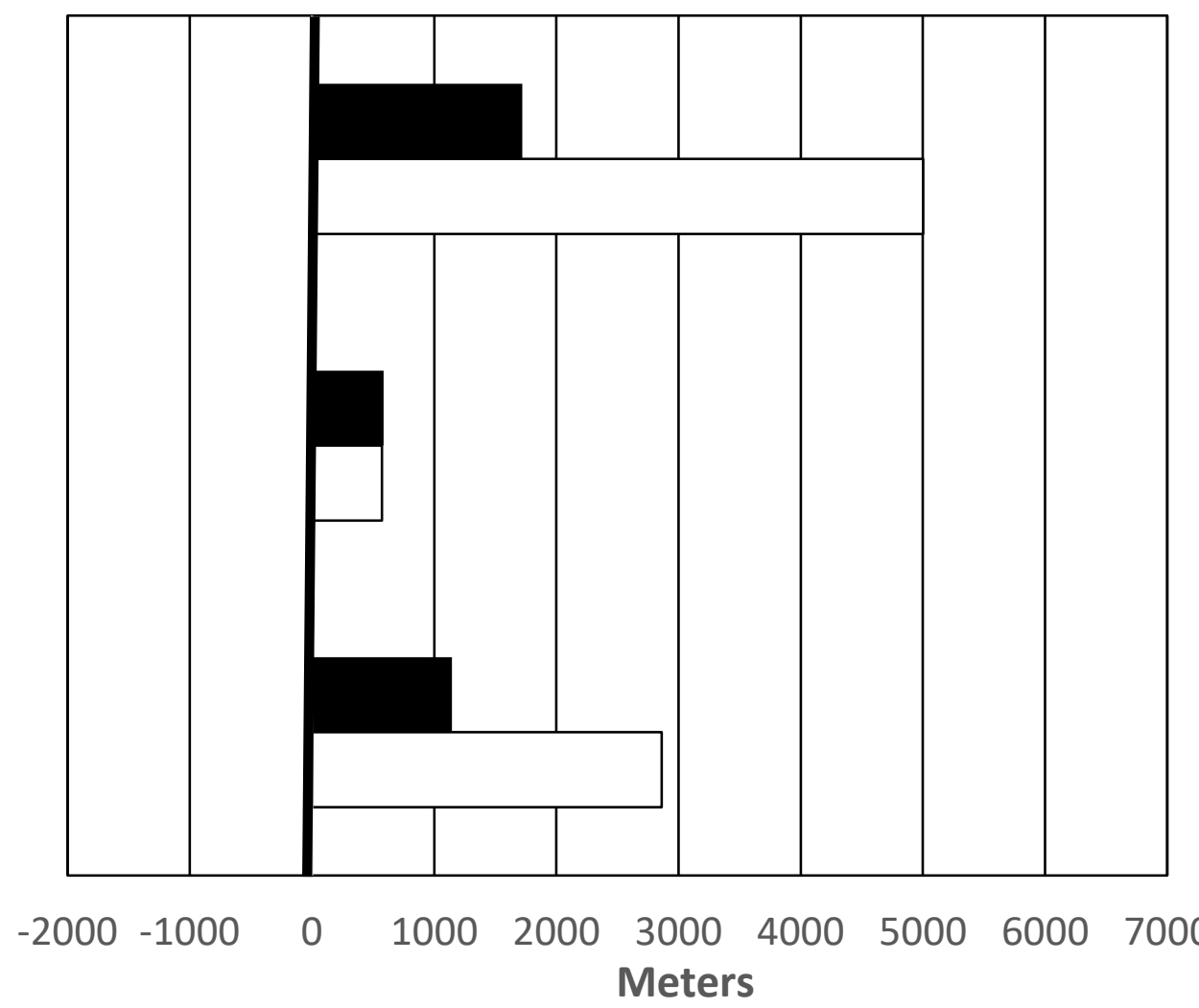

MOVEMENT/DAY (x100)

MEAN NET DISPERSAL

MEAN DISTANCE MOVED

- Brown Trout

$\square$ Brook Trout 
Figure 5. Dispersal Rates of Brook Trout tagged in the 2016 field season. Movement of fish in extreme tails of distribution (e.g. -160) moved downstream from tagging site, and all moved from the mainstem into tributary habitats

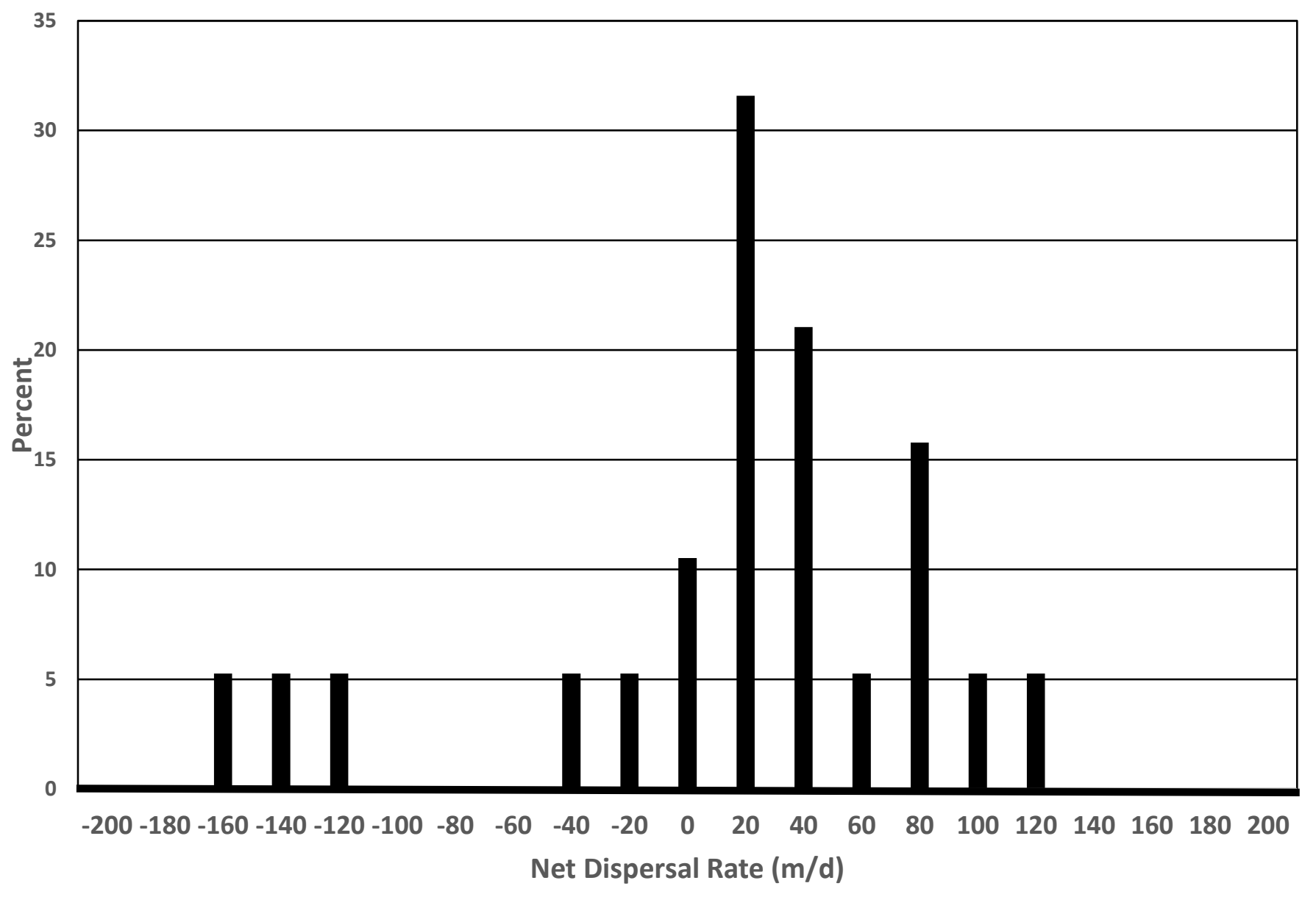


Figure 6. Hydrograph for the upper Shavers Fork system during the 2015 field season (June 1, 2015 - August 15, 2015). Peak values represent increased streamflow due to precipitation or rainfall events. Note relatively high discharge recorded with discrete rainfall events on June 26, 2015 and July 12, 2015. Data collected from gauging station located on Shaver's Fork near Cheat Bridge, USGS Station \#03067510. The "Measured Discharge" in the hydrograph represents a USGS calibration check on the gauging station.

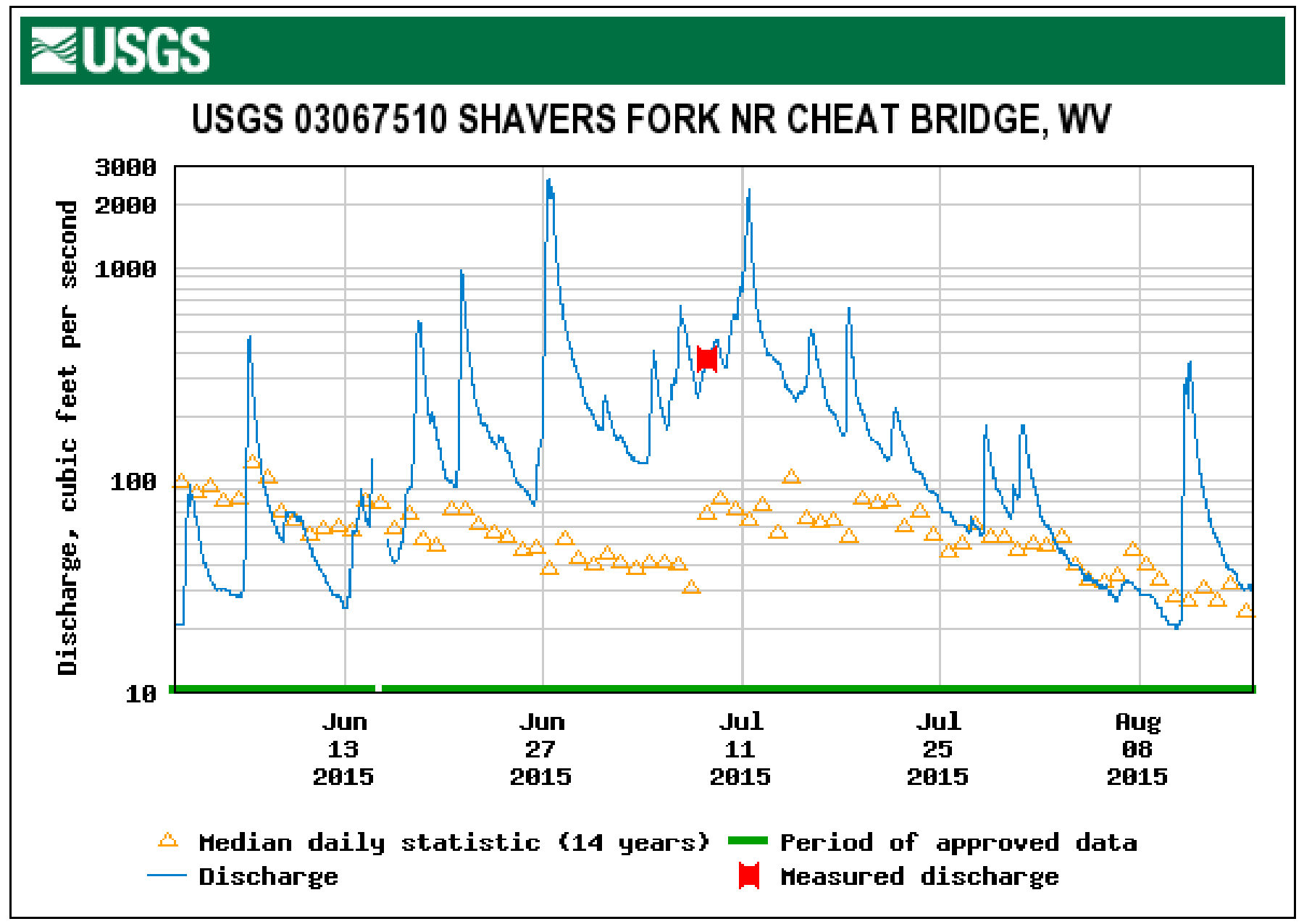

${ }^{*}$ Data and graph courtesy of United States Geological Survey 
Figure 7. Hydrograph for the upper Shavers Fork system during the 2016 field season (June 1, 2016 - August 15, 2016). Peak values represent increased streamflow due to precipitation or rainfall events. Note extremely high discharge ( 6000cfs) associated with the June 23, 2016 floods in eastern West Virginia. Data collected from gauging station located on Shaver's Fork near Cheat Bridge, USGS Station \#03067510. The "Measured Discharge" in the hydrograph represents a USGS calibration check on the gauging station.

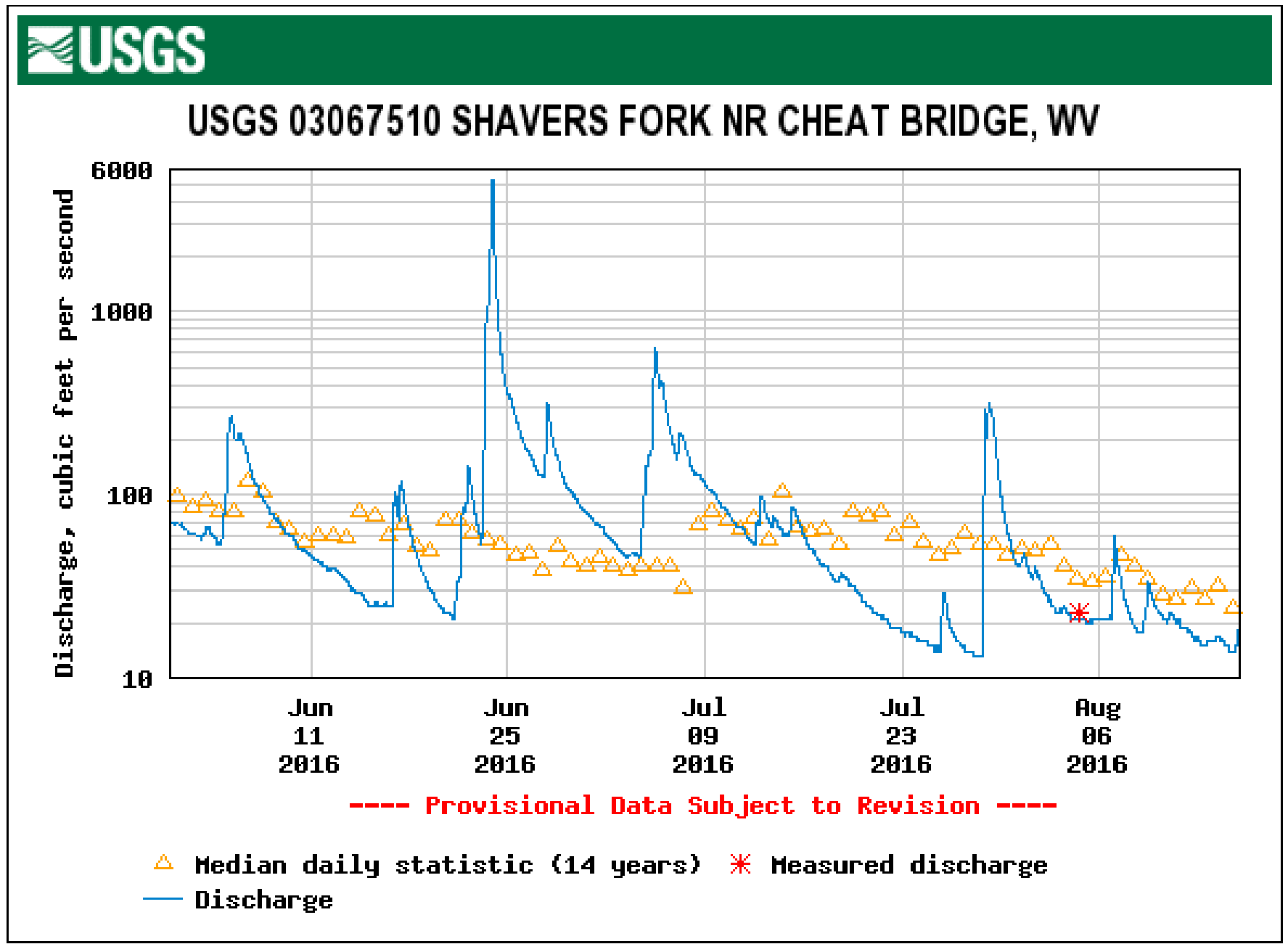

*Data and graph courtesy of United States Geological Survey 
Figure 8. Map showing movement of the single Brown Trout (SATR_1 / SATR_5) tagged in both the 2015 \& 2016 tracking seasons. SATR_1/5 exhibited nearly identical movement patterns in both seasons, moving from the tagging site of Beaver Creek roughly $3 \mathrm{~km}$ upstream to a constructed pool habitat located below Second Fork. In both field seasons, SATR_ $1 / 5$ was located in this structure pool at the start of mainstem tracks and remained there for the duration of the field season.

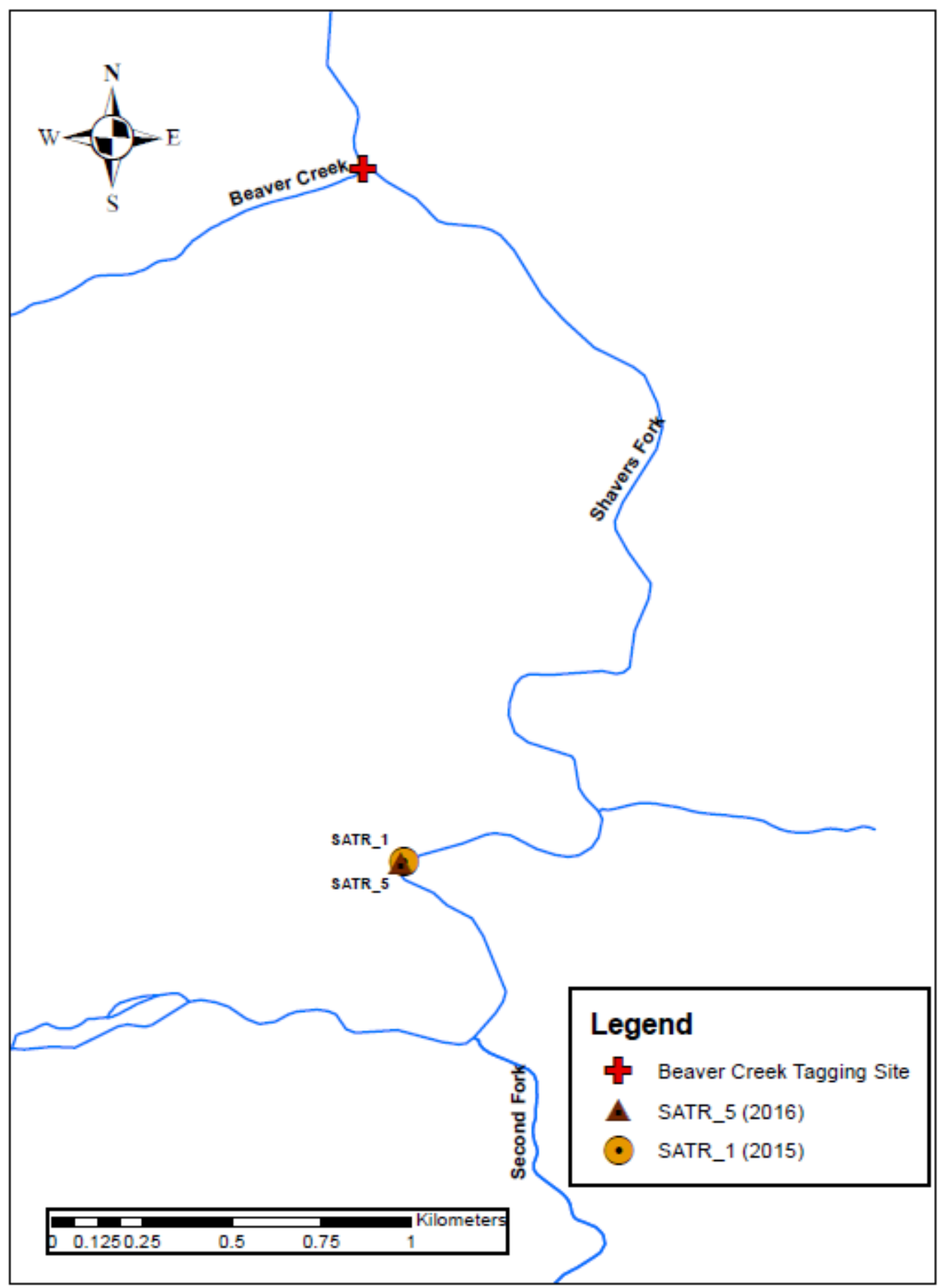


Figure 9. Cumulative frequency distributions of Brook and Brown Trout in the 2015 field season

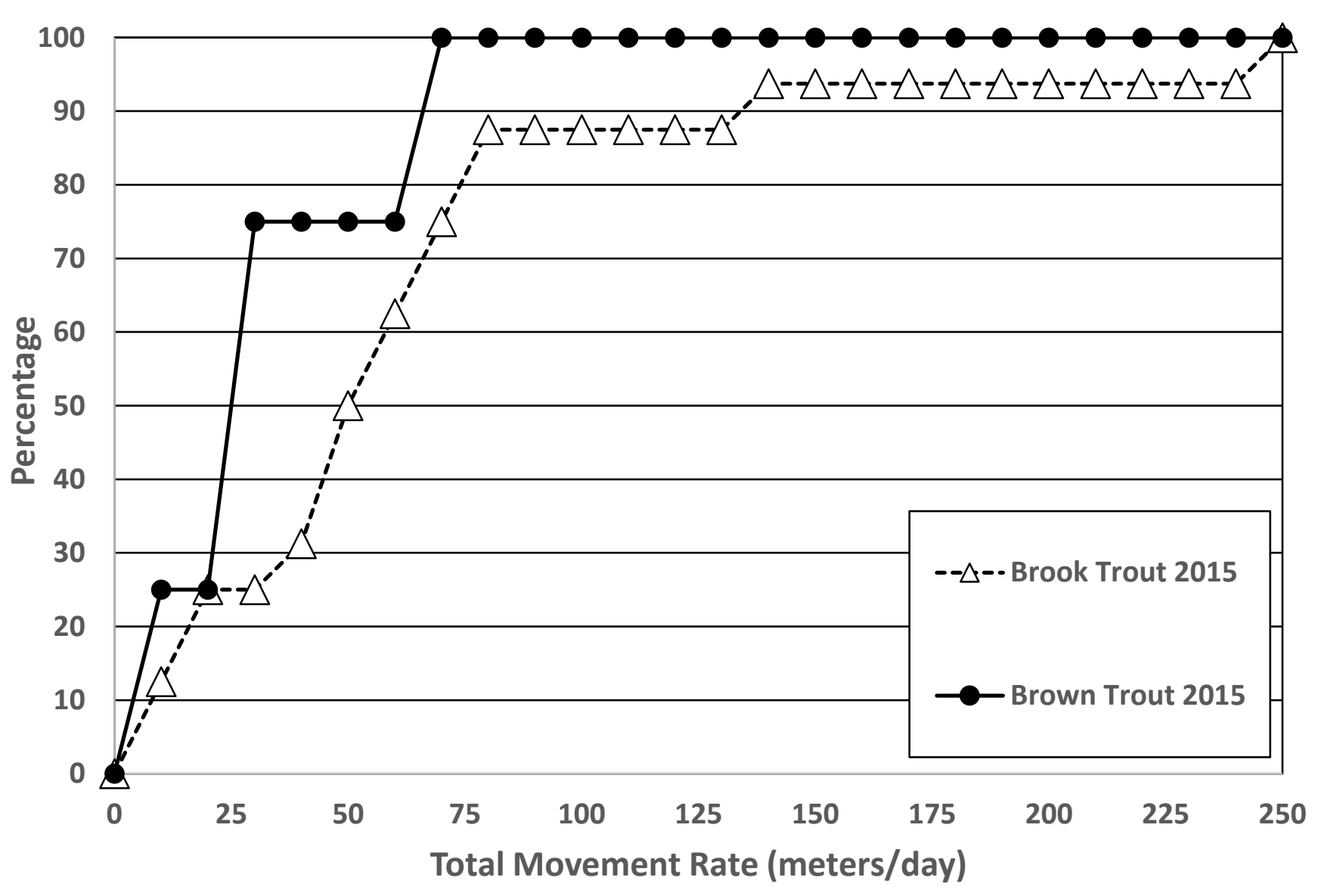


Figure 10. Cumulative Frequency distributions of Brook and Brown Trout in the 2016 field season.

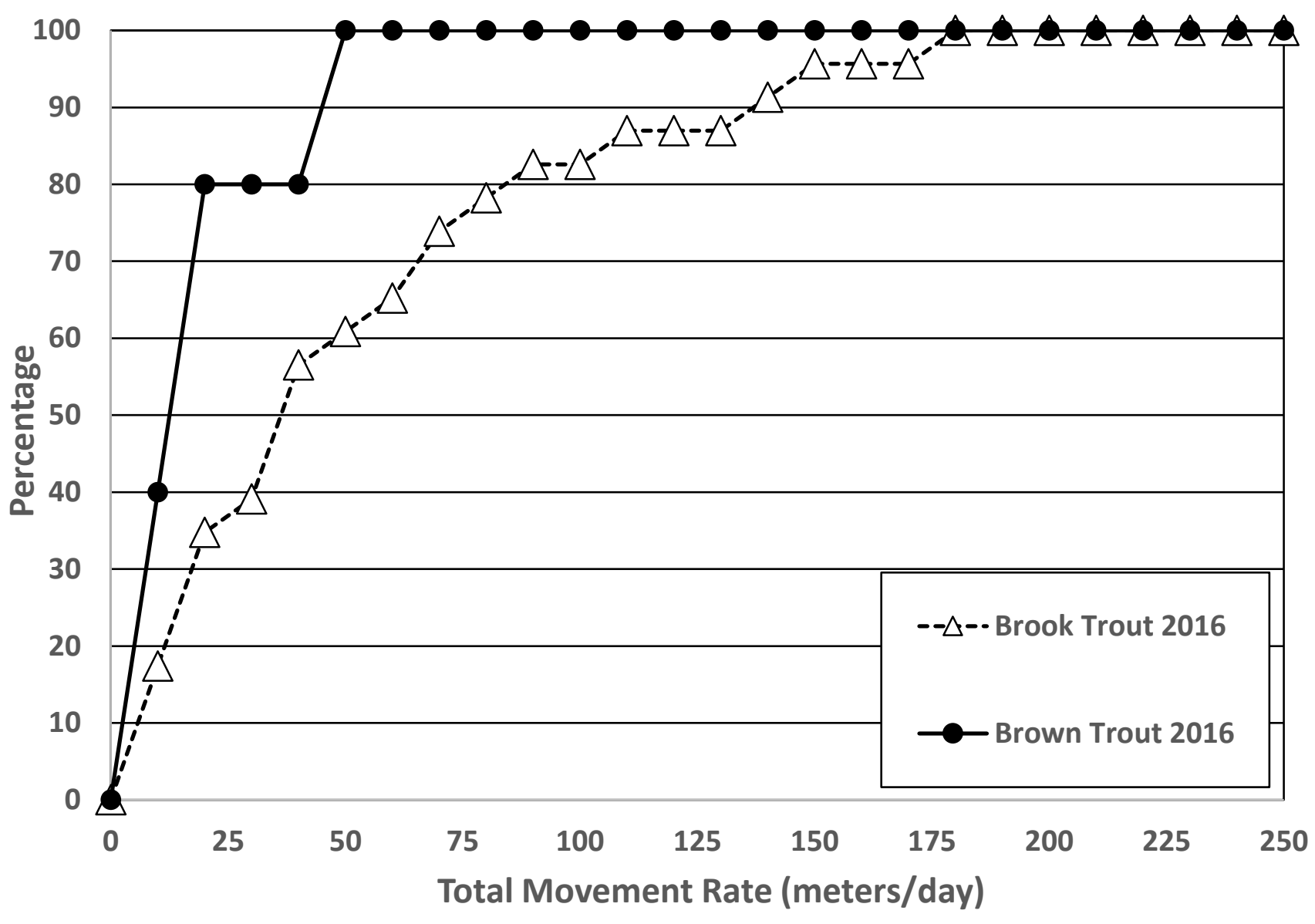


Figure 11. Dispersal rates for Brown Trout tagged in the 2015 field season

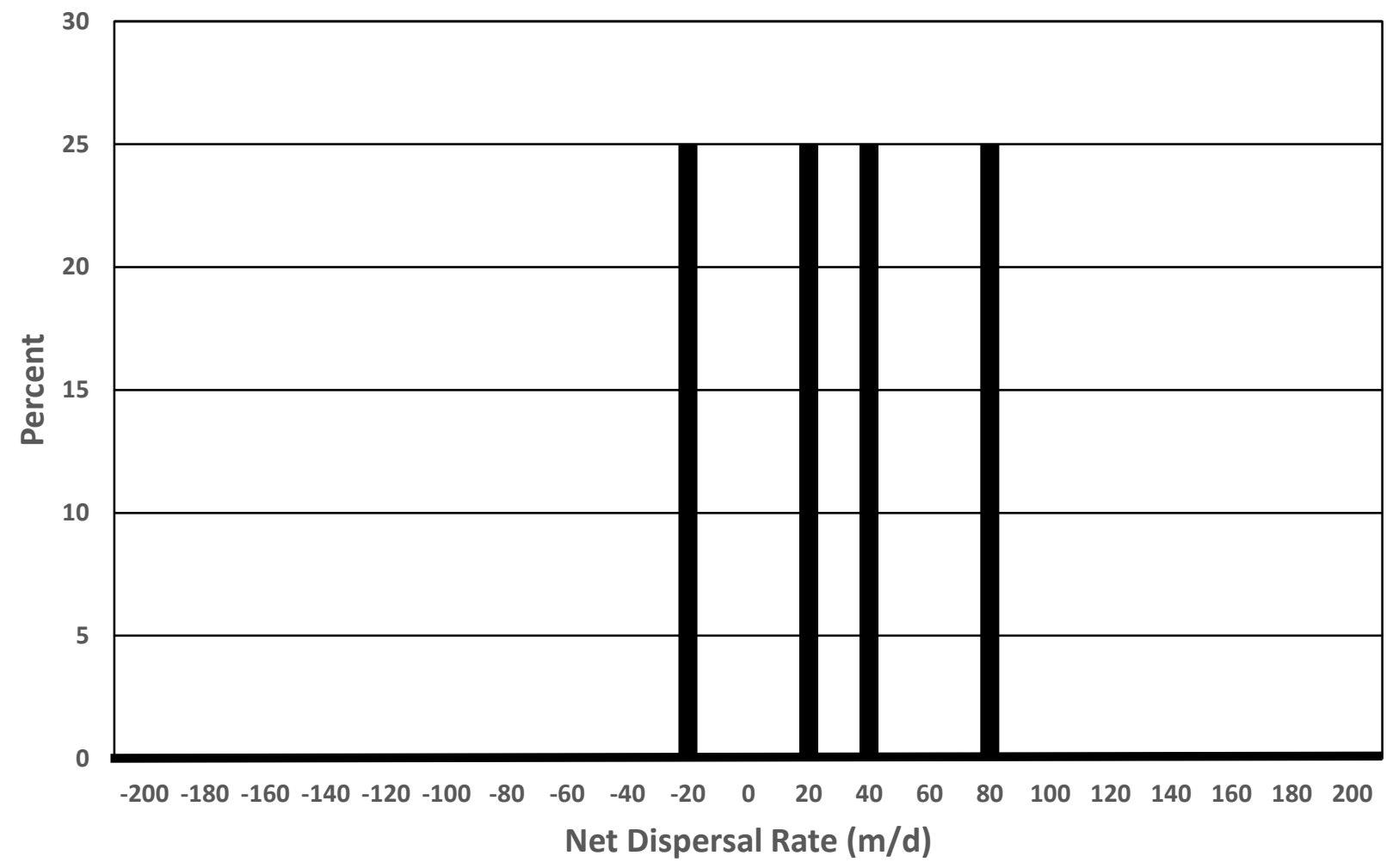


Figure 12. Dispersal rates for Brown Trout tagged in the 2016 field season

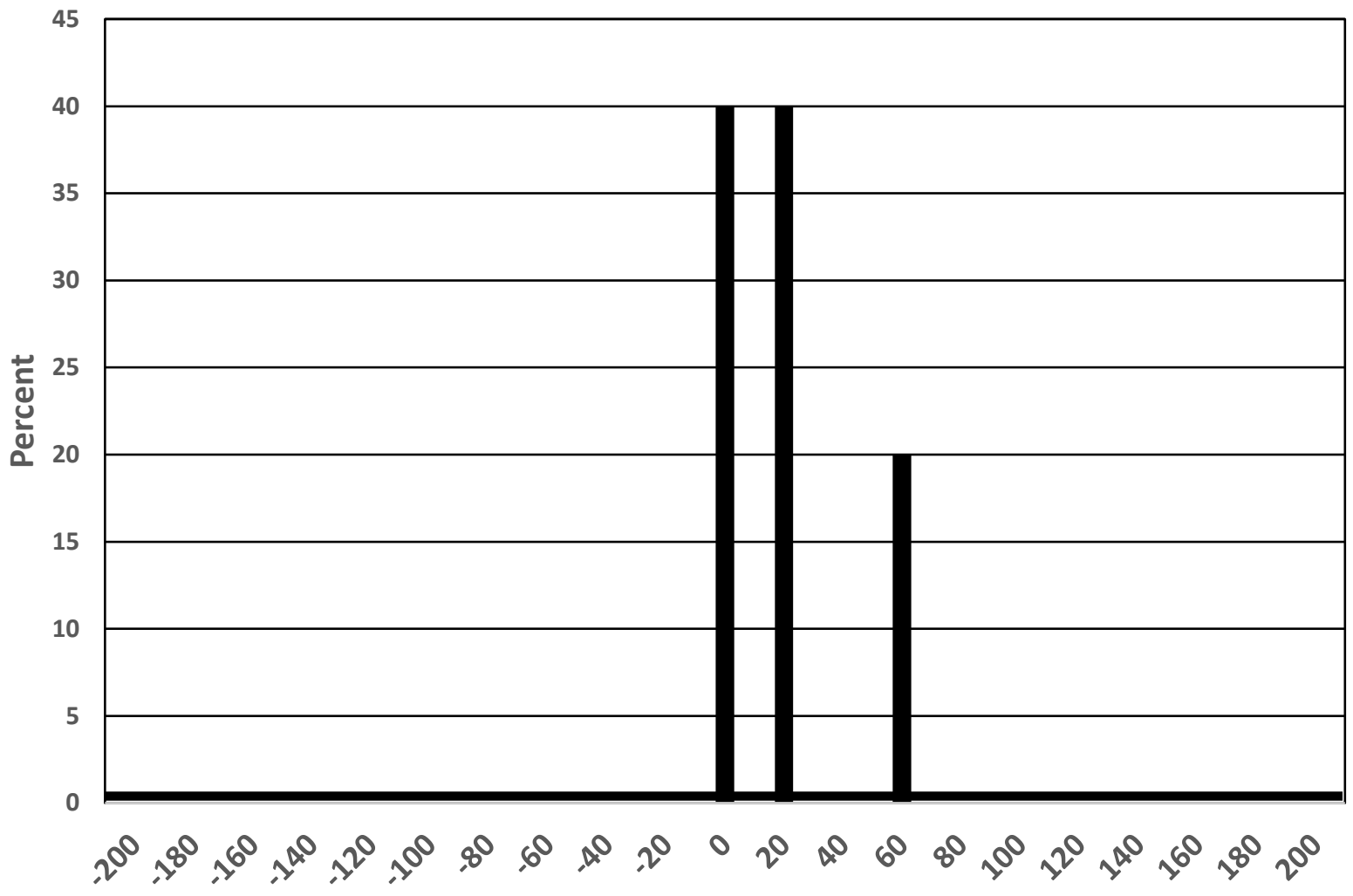

Net Dispersal Rate $(\mathrm{m} / \mathrm{d})$ 
Figure 13 Map of final tracking locations of Brook and Brown Trout tagged in the 2015 field season.

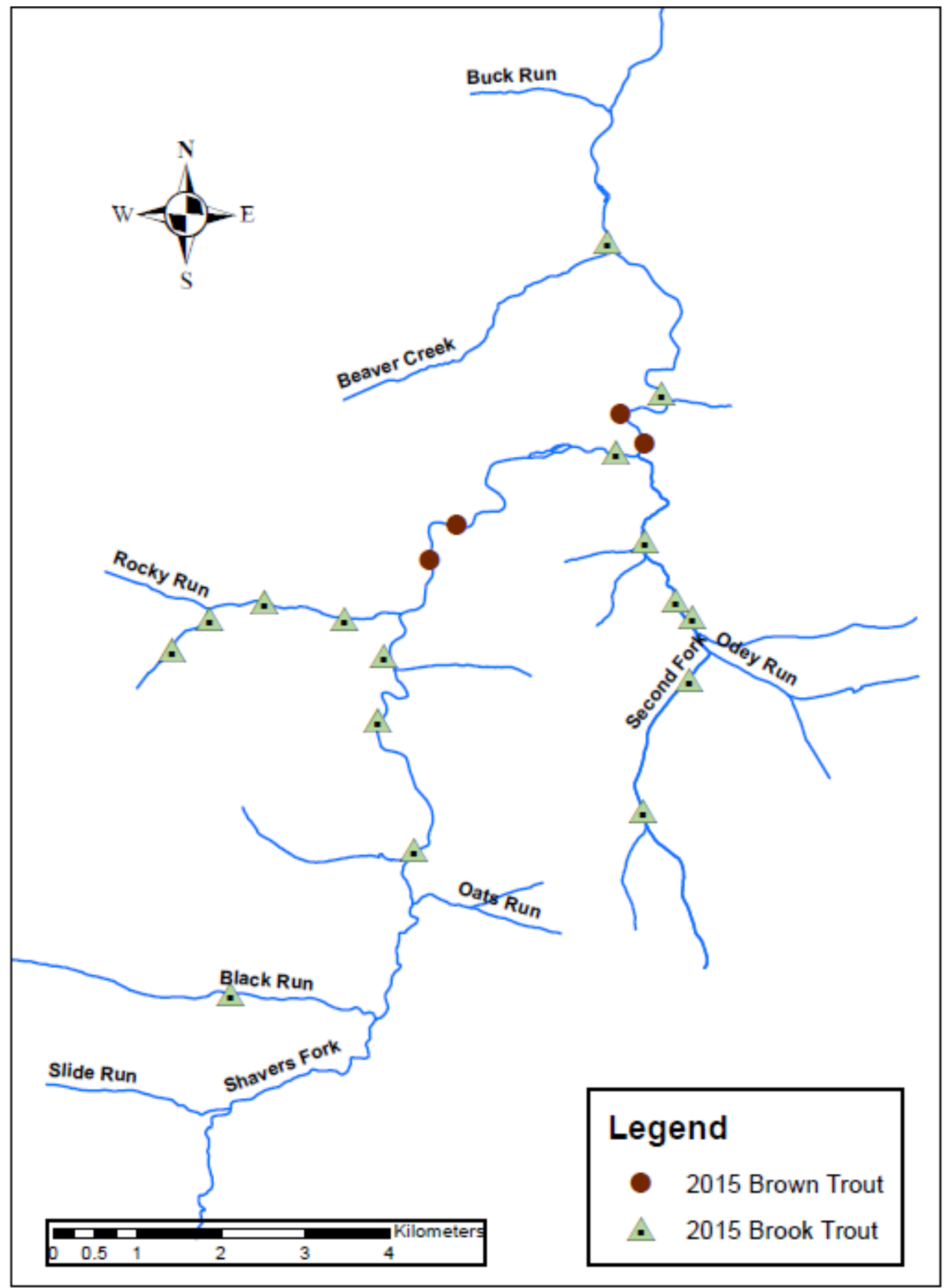


Figure 14. Map of the final tracking locations of Brook and Brown Trout tagged in the 2016 field season.

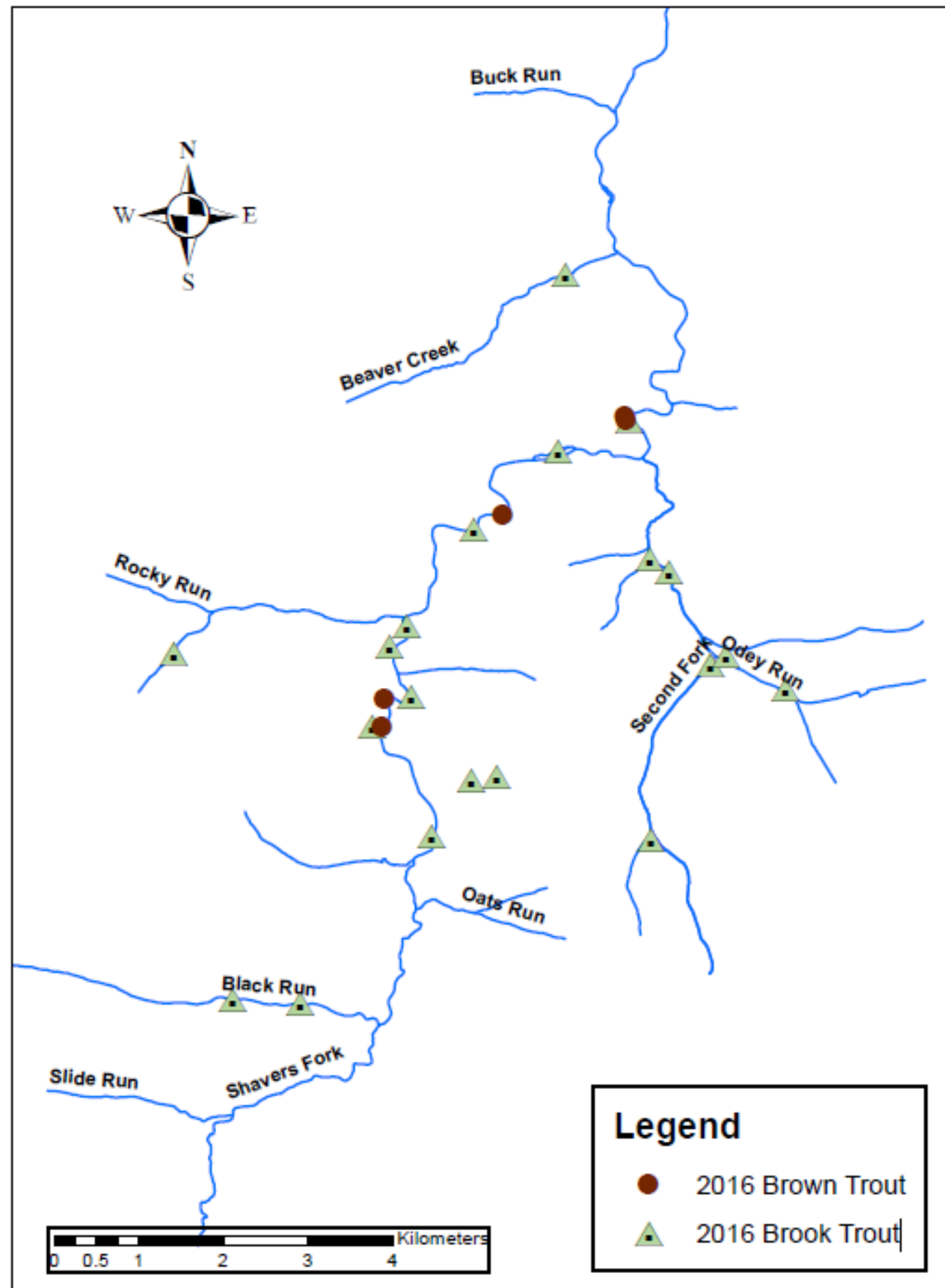


Figure 15. Photograph of the access point to the reconnected tributary Lamothe Hollow. Interlocking log jams provide small plunge pools and flow refuge for fish moving upstream into the tributary system. Lamothe Hollow is one of three major tributary systems with restored access on Shavers Fork.

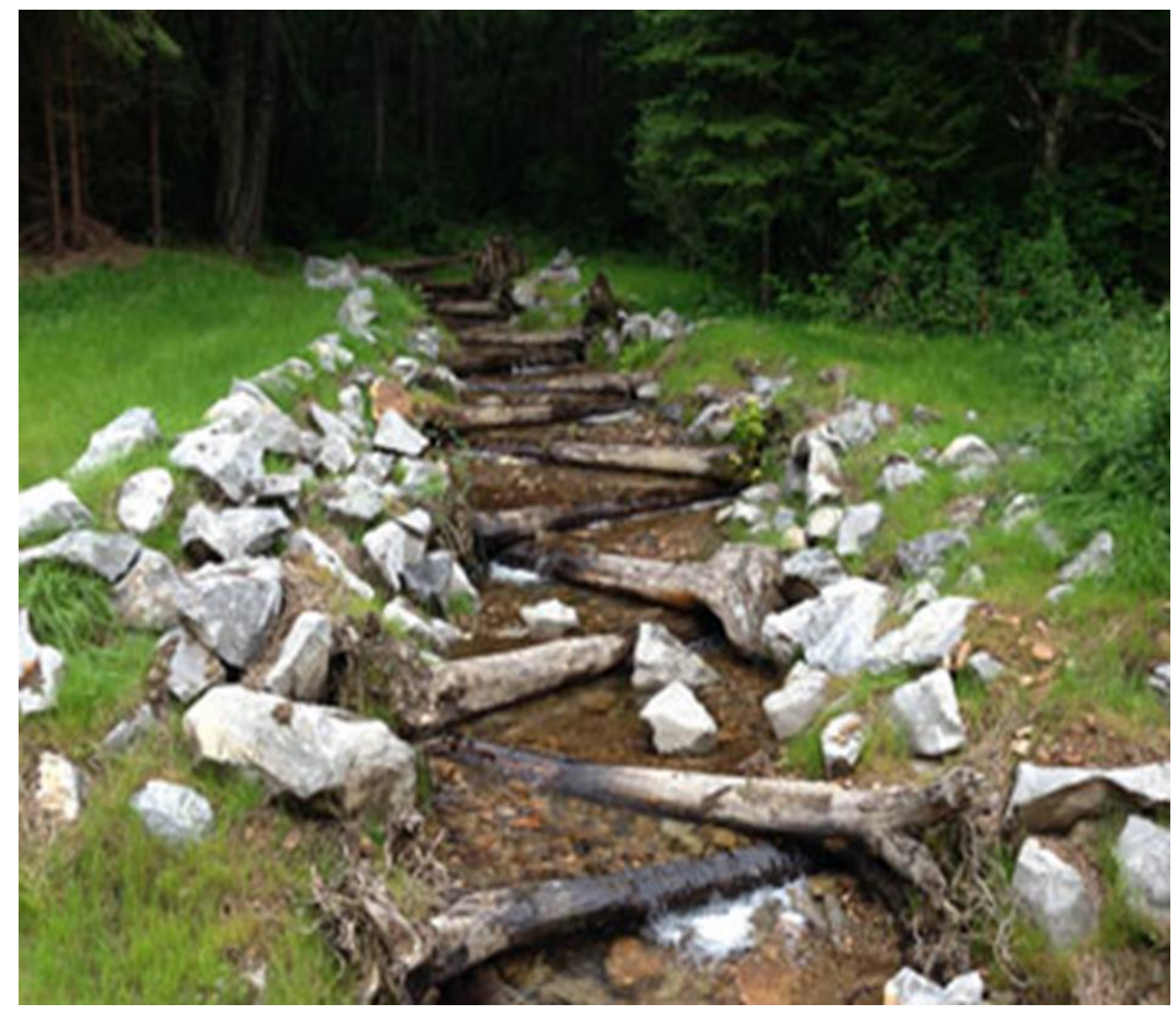


Figure 16. Photograph of the restored fish-access culvert on Oat's Run. This type of culvert has a step-gradient on the bottom rather than a straight 'chute', enabling fish to climb the culvert, facilitating access into the tributary systems and headwaters.

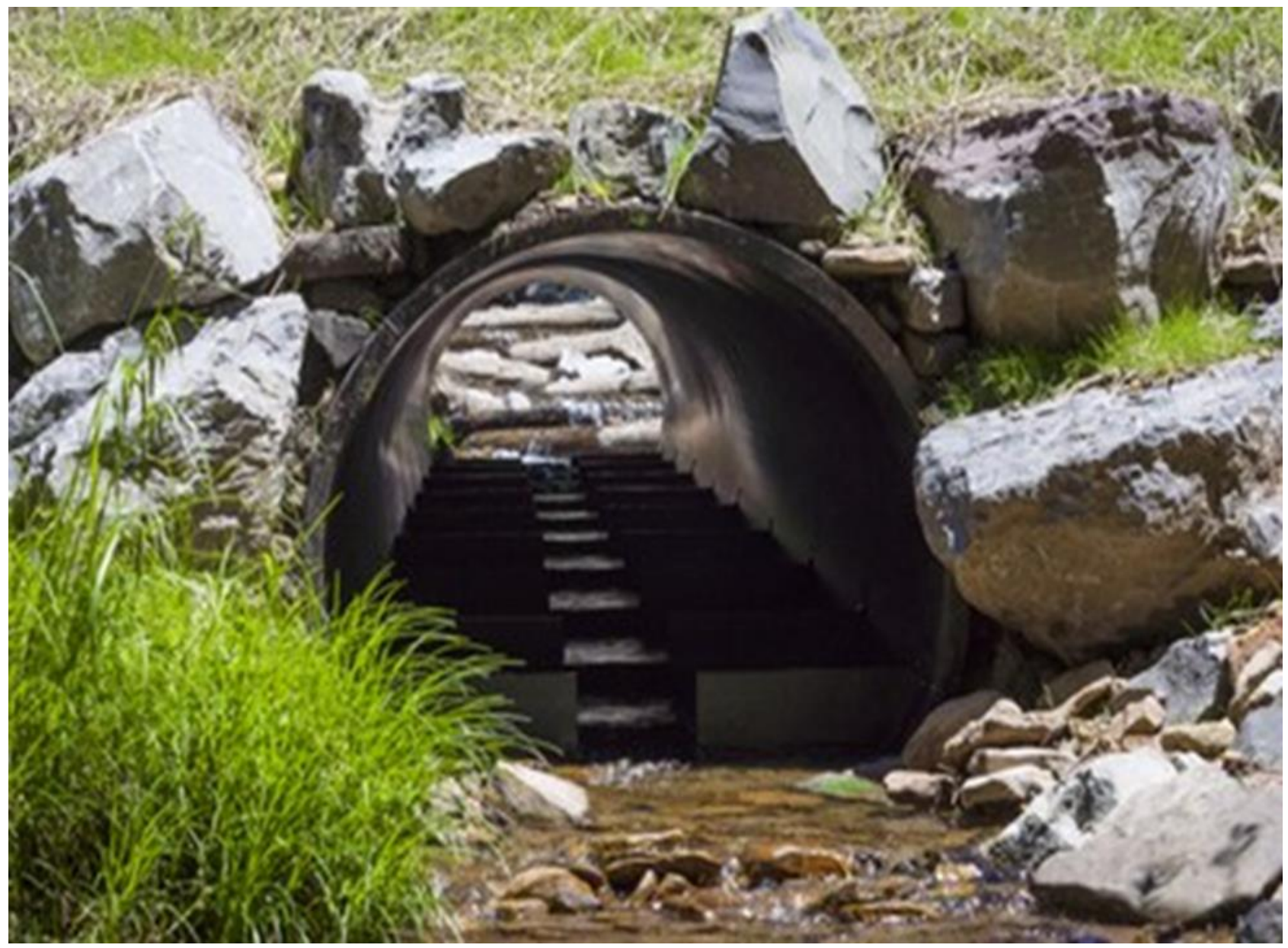


Figure 17. Map of fish located in Lamothe Hollow, a tributary with restored connectivity to the mainstem to facilitate fish access. These fish represent verifiable relationship with restoration activities on Shavers Fork. The locations of SAFO_36 and SAFO_44 were unreachable to fish prior to culvert removal and fish access restoration activities.

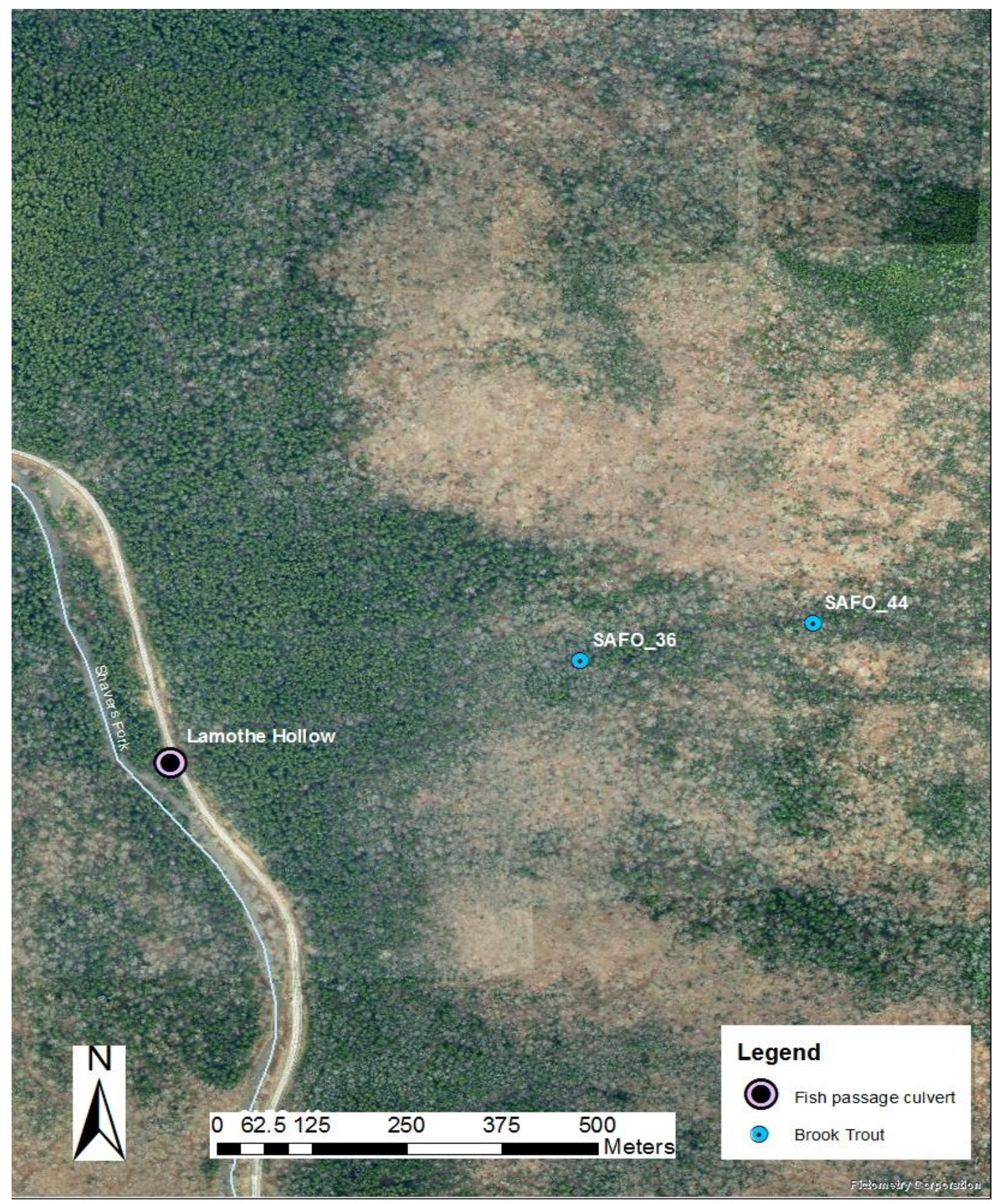


Figure 18. Hydraulic channel unit (HCU) association by Brook Trout in the 2015 field season. Observations were taken at the resolution of each track throughout the field season. HCUs were classified consistently with established habitat surveys on the mainstem of Shavers Fork.

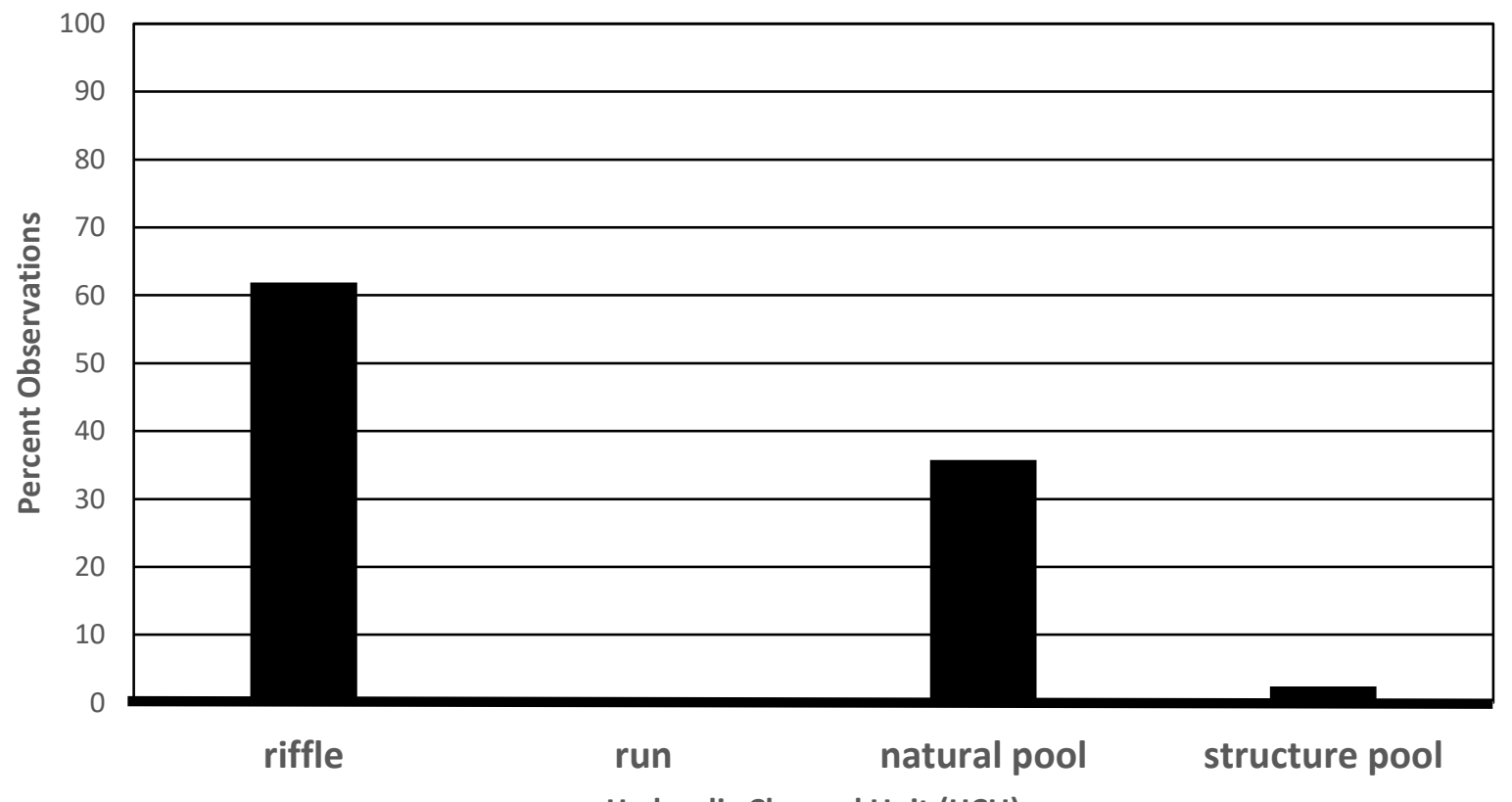

Hydraulic Channel Unit (HCU) 
Figure 19. Hydraulic channel unit (HCU) association by Brown Trout in the 2015 field season. Observations were taken at the resolution of each track throughout the field season. HCUs were classified consistently with established habitat surveys on the mainstem of Shavers Fork.

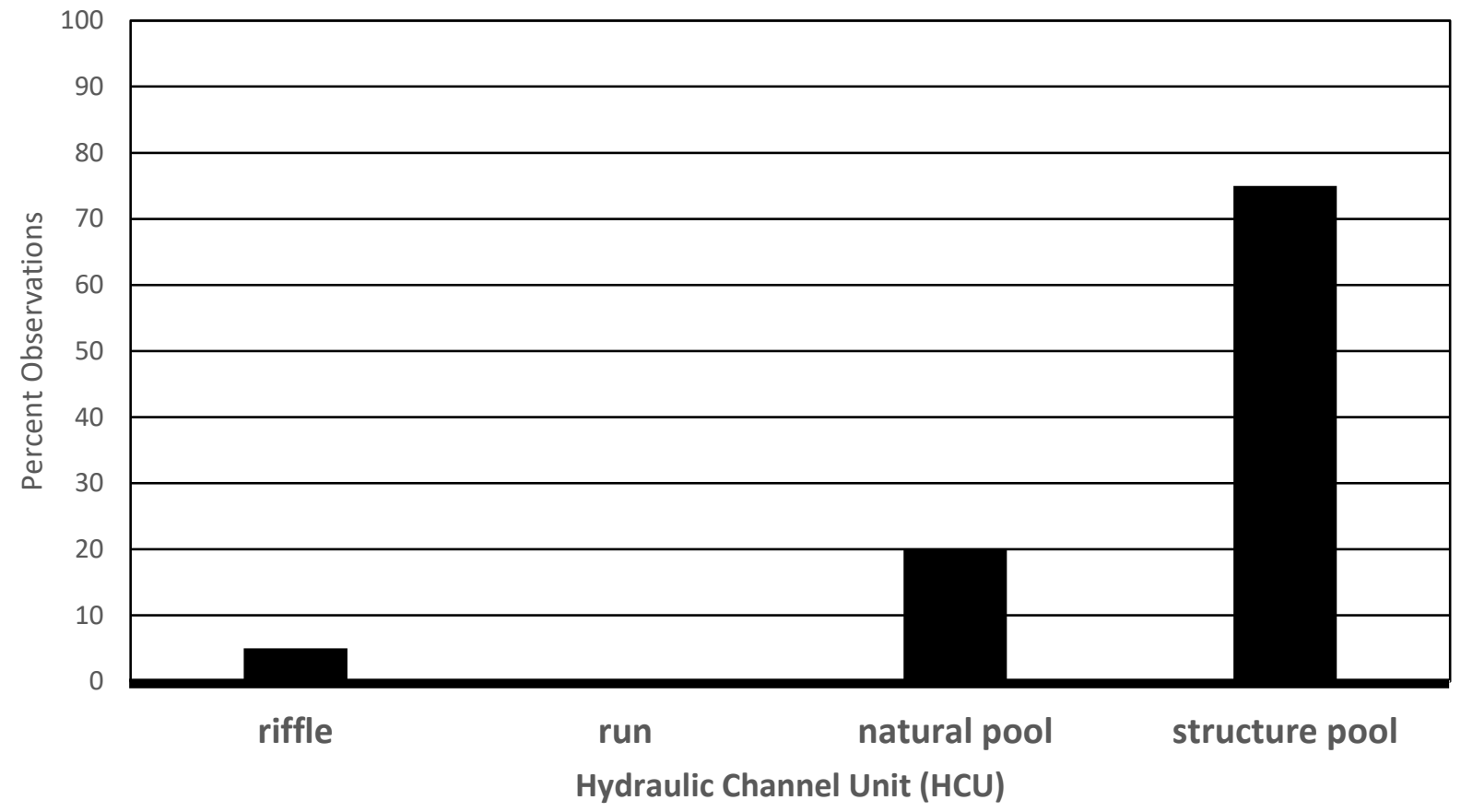


Figure 20. Hydraulic channel unit (HCU) association by Brook Trout in the 2016 field season. Observations were taken at the resolution of each track throughout the field season. HCUs were classified consistently with established habitat surveys on the mainstem of Shavers Fork.

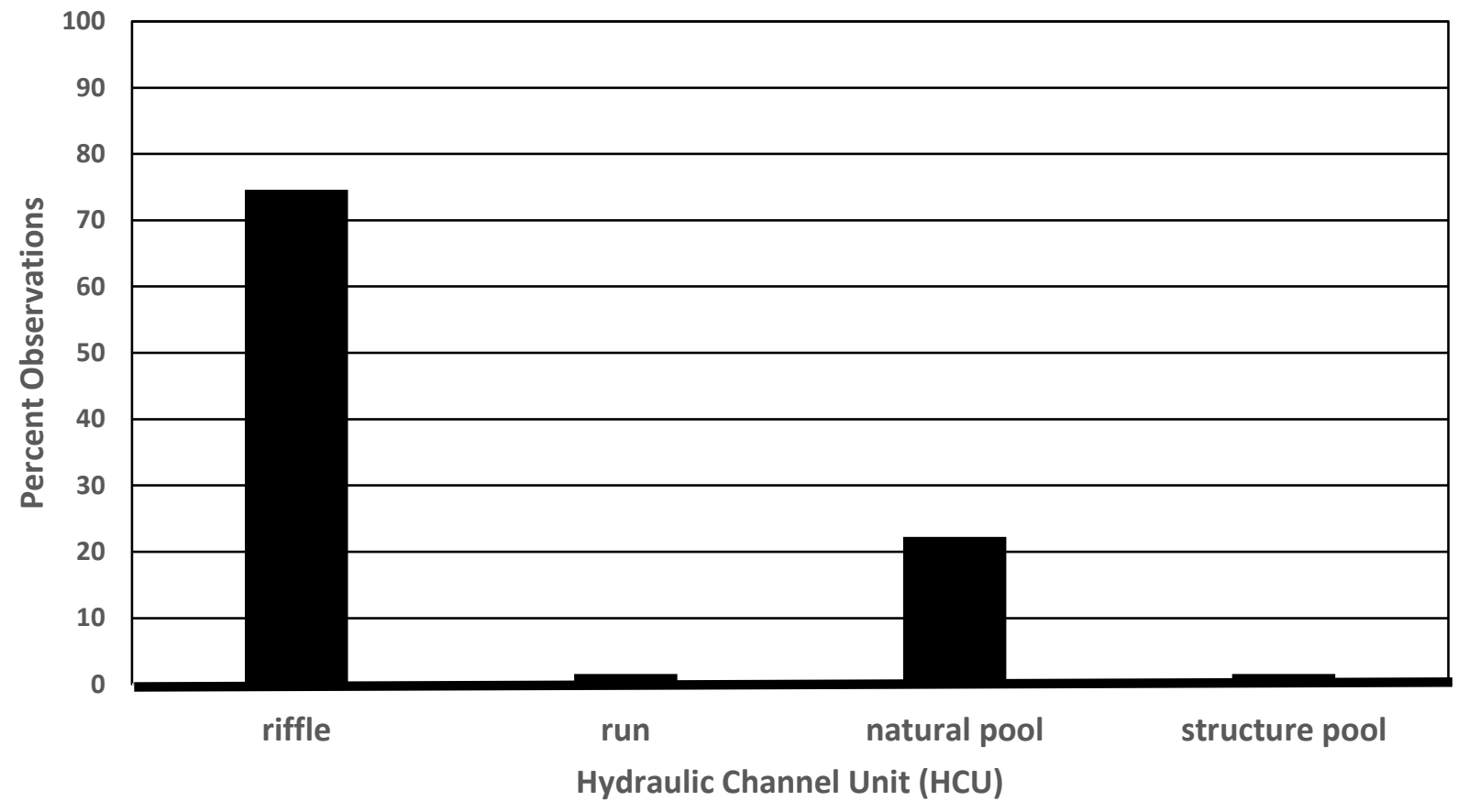


Figure 21. Hydraulic channel unit (HCU) association by Brown Trout in the 2016 field season. Observations were taken at the resolution of each track throughout the field season. HCUs were classified consistently with established habitat surveys on the mainstem of Shavers Fork.

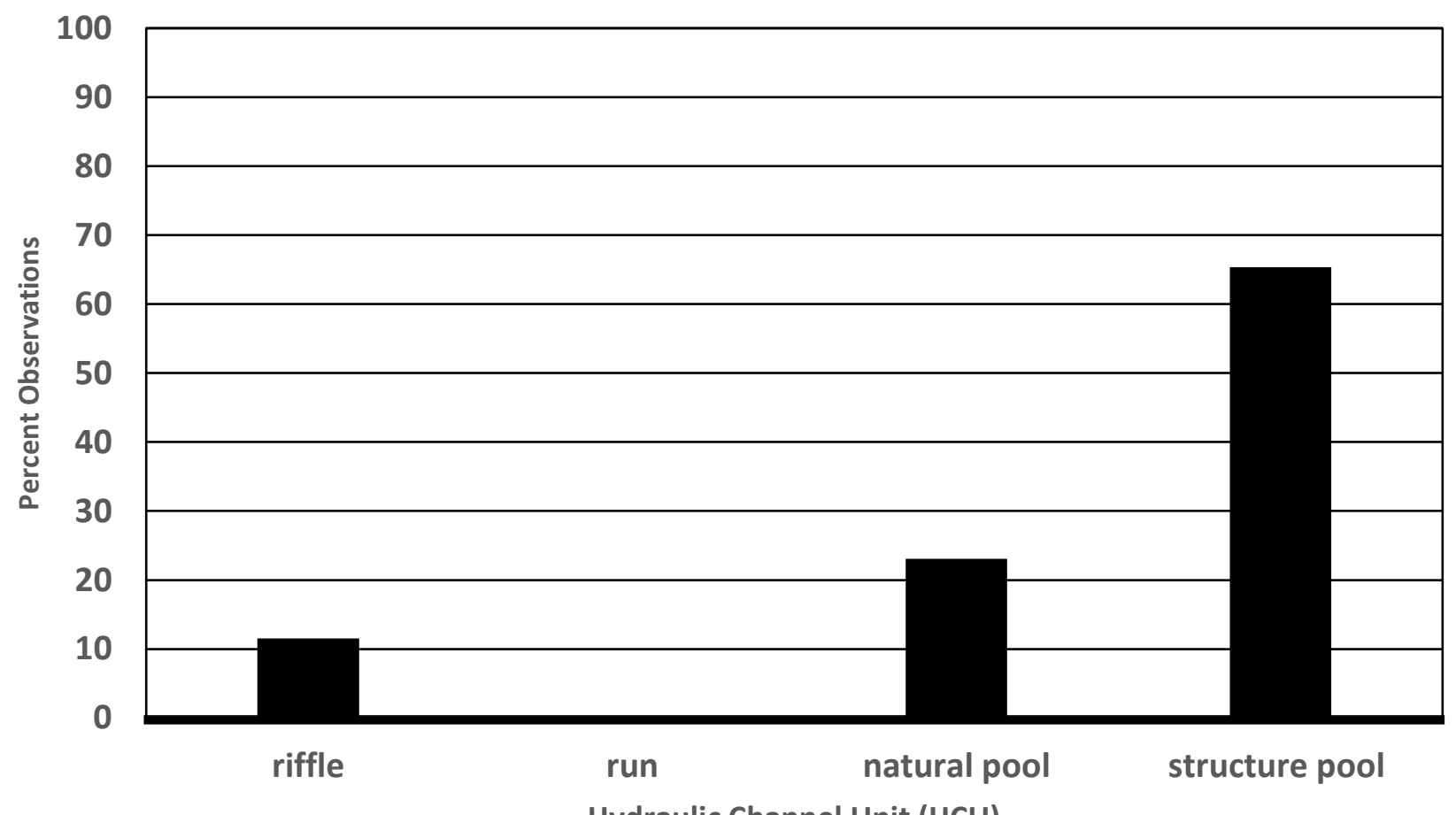

Hydraulic Channel Unit (HCU) 
Figure 22. Closeup aerial photograph of the intermittent floodplain side channel utilized by Brook Trout in both the 2015 and 2016 field seasons. This image shows precise final tracking locations for SAFO_26 and SAFO_50. Both fish associated with deeply incised banks and lateral coldwater seeps in this floodplain side channel.

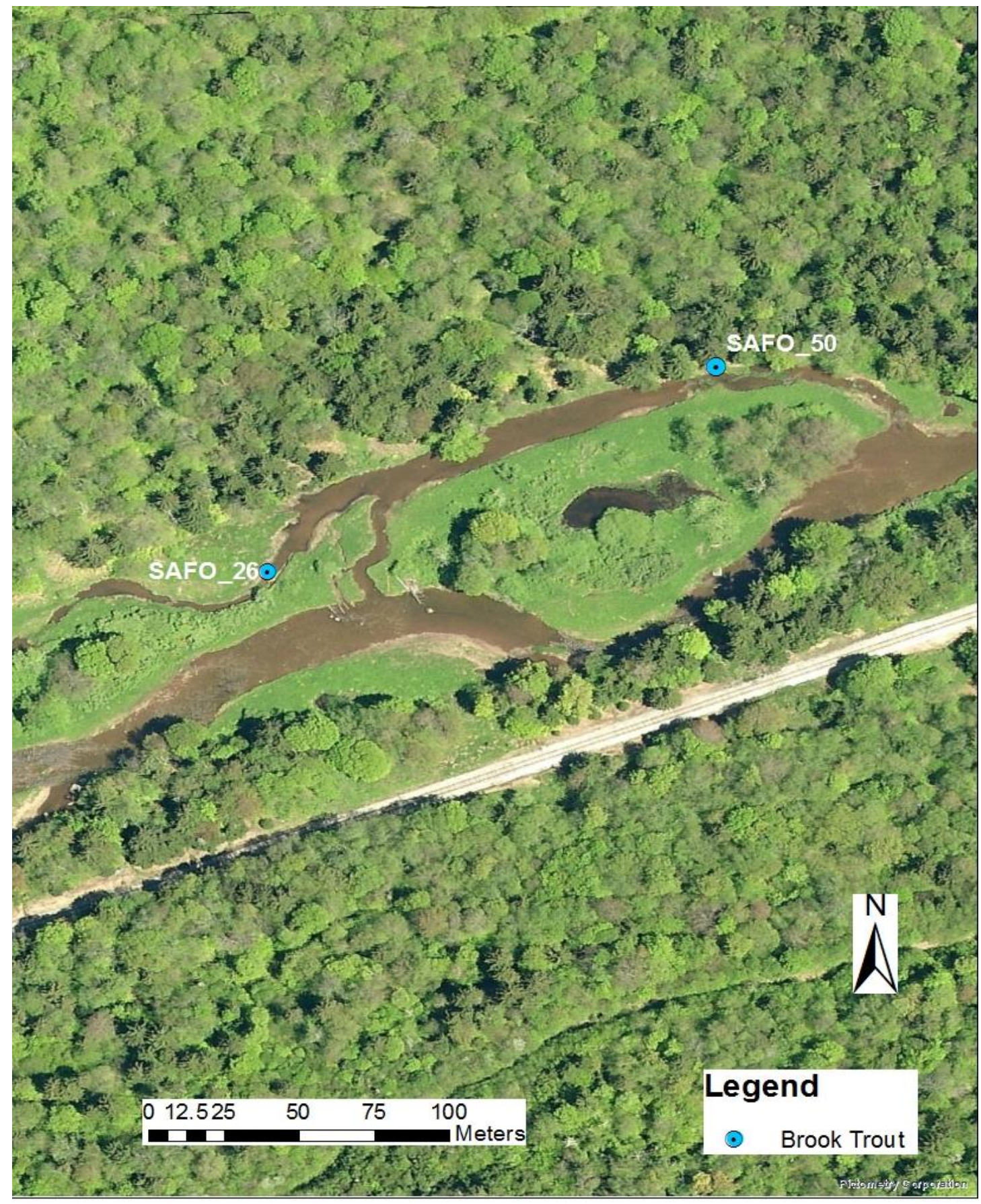


Figure 23. Map showing representative final locations for Brook Trout tagged at the Below Second Fork and East-West surgery sites in the 2016 field season.

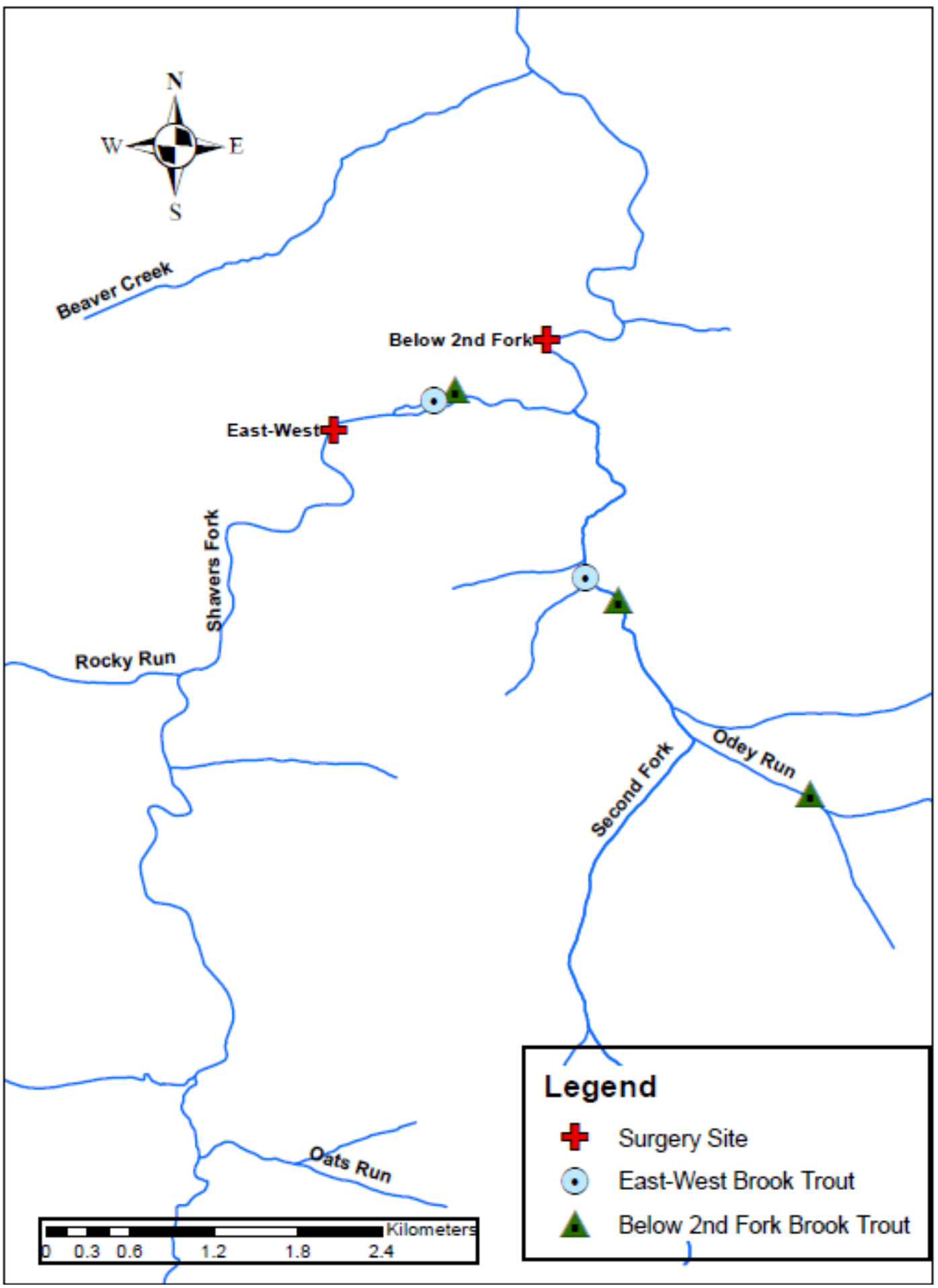


Figure 24. Map of representative final tracking locations for Brook Trout tagged at the 'Above Ryan's Bend' surgery site.

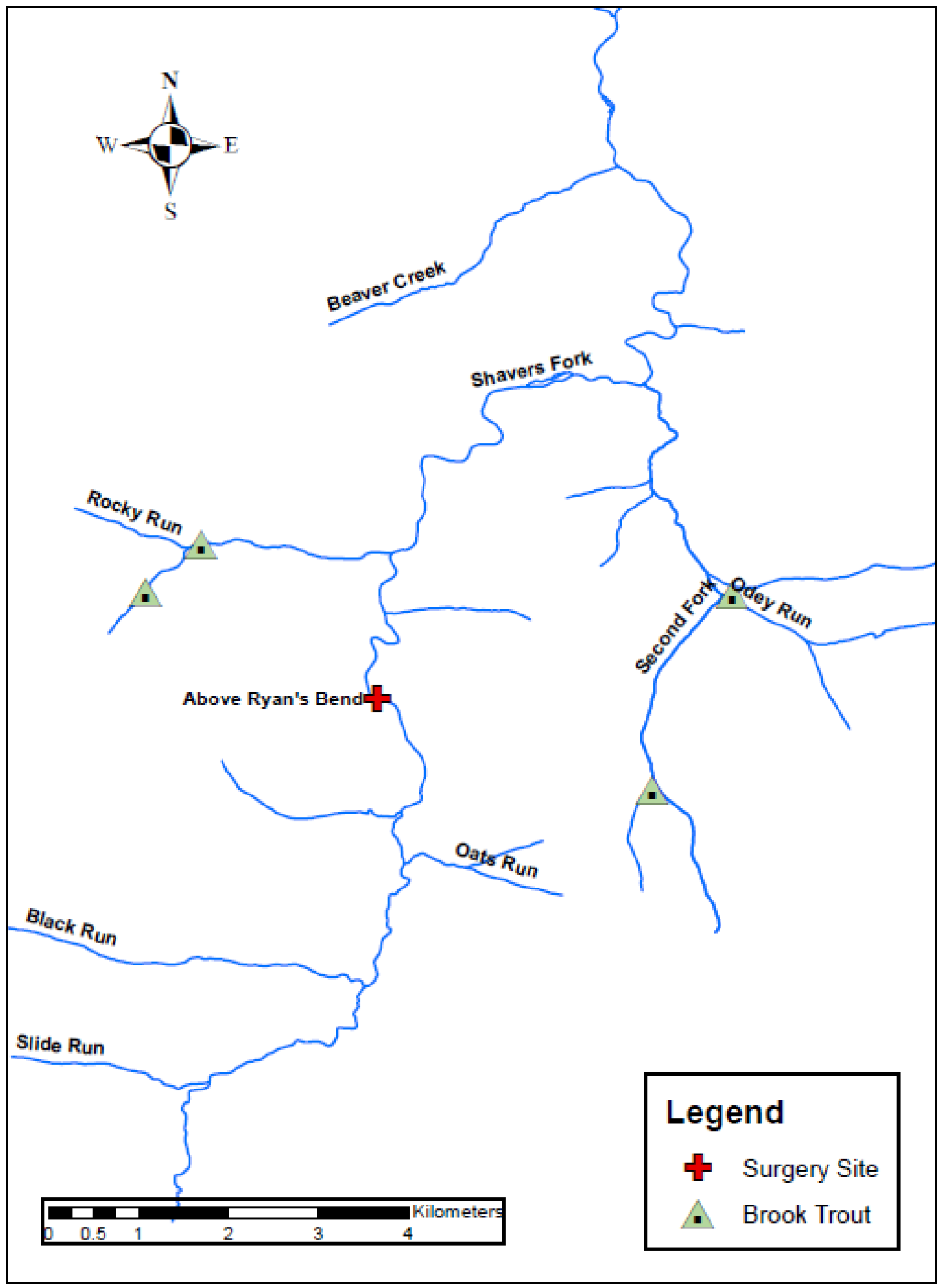


Figure 25. Map of surgery locations for the 2015 \& 2016 field seasons

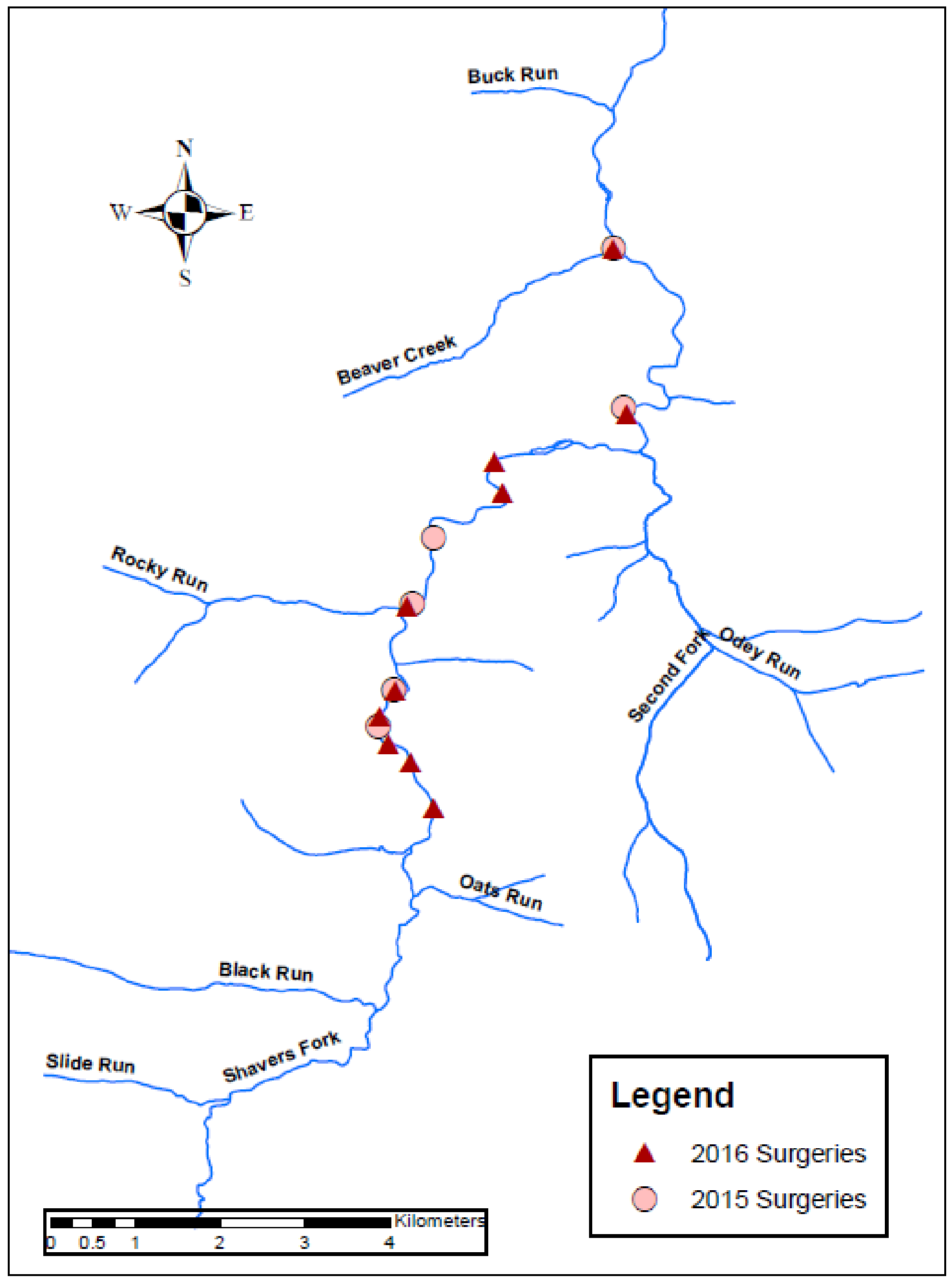

